\title{
Estrogen receptors $\alpha, \beta$ and GPER in the CNS and trigeminal system - molecular and functional aspects
}

Karin Warfvinge ${ }^{1,2}$, Diana N. Krause ${ }^{2,3+}$, Aida Maddahi ${ }^{1 \dagger}$, Jacob C. A. Edvinsson ${ }^{1,4}$, Lars Edvinsson ${ }^{1,2,5^{*}}$ (D) and Kristian A. Haanes ${ }^{1}$

\begin{abstract}
Background: Migraine occurs 2-3 times more often in females than in males and is in many females associated with the onset of menstruation. The steroid hormone, 17ß-estradiol (estrogen, E2), exerts its effects by binding and activating several estrogen receptors (ERs). Calcitonin gene-related peptide (CGRP) has a strong position in migraine pathophysiology, and interaction with CGRP has resulted in several successful drugs for acute and prophylactic treatment of migraine, effective in all age groups and in both sexes.

Methods: Immunohistochemistry was used for detection and localization of proteins, release of CGRP and PACAP investigated by ELISA and myography/perfusion arteriography was performed on rat and human arterial segments.

Results: ERa was found throughout the whole brain, and in several migraine related structures. ER $\beta$ was mainly found in the hippocampus and the cerebellum. In trigeminal ganglion (TG), ERa was found in the nuclei of neurons; these neurons expressed CGRP or the CGRP receptor in the cytoplasm. G-protein ER (GPER) was observed in the cell membrane and cytoplasm in most TG neurons. We compared TG from males and females, and females expressed more ER receptors. For neuropeptide release, the only observable difference was a baseline CGRP release being higher in the pro-estrous state as compared to estrous state. In the middle cerebral artery (MCA), we observed similar dilatory ER-responses between males and females, except for vasodilatory ER $\beta$ which we observed only in female arteries.

Conclusion: These data reveal significant differences in ER receptor expression between male and female rats. This contrasts to CGRP and PACAP release where we did not observe discernable difference between the sexes. Together, this points to a hypothesis where estrogen could have a modulatory role on the trigeminal neuron function in general rather than on the acute CGRP release mechanisms and vasomotor responses.
\end{abstract}

Keywords: Estrogen receptors, CGRP, PACAP, Immunohistochemistry, Myography, Brain, Trigeminal ganglion, MCA

\footnotetext{
* Correspondence: lars.edvinsson@med.lu.se

${ }^{\dagger}$ Diana N. Krause and Aida Maddahi contributed equally to this work.

'Department of Clinical Experimental Research, Glostrup Research Institute, Rigshospitalet, Glostrup, Denmark

${ }^{2}$ Division of Experimental Vascular Research, Department of Clinical Sciences, Lund University Hospital, Lund, Sweden

Full list of author information is available at the end of the article
}

(c) The Author(s). 2020 Open Access This article is licensed under a Creative Commons Attribution 4.0 International License, which permits use, sharing, adaptation, distribution and reproduction in any medium or format, as long as you give appropriate credit to the original author(s) and the source, provide a link to the Creative Commons licence, and indicate if changes were made. The images or other third party material in this article are included in the article's Creative Commons licence, unless indicated otherwise in a credit line to the material. If material is not included in the article's Creative Commons licence and your intended use is not permitted by statutory regulation or exceeds the permitted use, you will need to obtain permission directly from the copyright holder. To view a copy of this licence, visit http://creativecommons.org/licenses/by/4.0/ The Creative Commons Public Domain Dedication waiver (http://creativecommons.org/publicdomain/zero/1.0/) applies to the data made available in this article, unless otherwise stated in a credit line to the data. 


\section{Introduction}

Migraine is a neurological disorder that affects $15 \%$ of the global population, predominates in the most active period of life and has enormous socioeconomic impact on society and family [1]. Migraine occurs 2-3 times more often in females than in males and is in many females associated with onset of menstruation [2]. This has resulted in much work aimed to unravel the role of sex hormones on migraine pathophysiology and to alleviate symptoms in females by substitution of sex hormones [3]. The steroid hormone, 17ß-estradiol (estrogen, $\mathrm{E}_{2}$ ), primarily produced in the female ovaries, has hence taken a dominant role in explanations of sex difference in migraine prevalence. Estrogen exerts its effects by binding and activating several estrogen receptors (ERs). In addition to the ovaries, fat cells produce active estrogen precursors in both sexes, and this is also the major site for formation of estrogen after menopause. Estrogen is further produced in the brain and in arterial walls [4]. Despite the possible negative effect on migraine prevalence linked to estrogen, there are several beneficial estrogenic effects, which include anti-apoptotic, anti-inflammatory and anti-oxidant properties as well as its ability to increase cerebral blood flow [5].

The two main ER, $\alpha$ and $\beta$, were originally thought only to act as transcription factors and appear to be located predominantly in synapses, axons, dendrites and dendritic spines $[6,7]$. In contrast to the original hypotheses of being pure modulators of transcription, both ER $\alpha$ and ER $\beta$ localize in many cells to the plasma membrane (5-10\% of total cellular ER) and to cytoplasmic organelles including mitochondria and endoplasmic reticulum [8]. The newest addition is the G proteincoupled estrogen receptor 1 (GPER) which is localized to the endoplasmic reticulum and may contribute to normal estrogen physiology as well as pathophysiology [9]. GPER function to regulate synaptic plasticity, at least in part, by acting on synaptic proteins [10]. Not much is known about the function of this receptor in males, despite evidence that points towards possible sexual dimorphism [11].

Calcitonin gene-related peptide (CGRP) has a strong position in migraine pathophysiology [12]. Thus, monoclonal antibodies and gepants are examples of the rapidly growing body of medications designed to modify CGRP mechanisms in the trigeminovascular system [13] (TVS); these are successful drugs for acute and prophylactic treatments of migraine in all age groups and in both sexes [14]. However, new targets are needed [15].

Besides of genomic effects that induce activation of nuclear receptors, transcription and translation, estrogen has been shown to exert non-genomic acute effects on vascular tone such as vasodilatation by $\mathrm{Ca}^{2+}$ channel antagonistic effects that inhibits extracellular influx of $\mathrm{Ca}^{+}[16]$ and modulation of the Rho/Rho kinase pathway and phosphorylation of myosin light chain [17] as well as via an endothelial effect mediated via release of nitric oxide [18].

The most striking link between estrogen and migraine is that in biologically-predisposed women, migraine attacks are triggered by a decline in plasma estrogen concentrations in the late luteal (premenstrual) phase of the menstrual cycle $[19,20]$. On the contrary, phases of rising estrogen levels appear to protect against migraine [3]. A key question is, however, why does estrogen affect migraine mechanisms in some but not in others? The presence of sex hormone receptors in the TVS suggests that trigeminal neurons are sensitive to variations in the levels of these hormones [21] and some of this could be linked to oxytocin [22].

We asked the questions: where are the estrogen receptors expressed in the CNS and in the TVS, using a palette of specific antibodies. Further we specifically looked at difference in the trigeminal ganglion (TG) between males and females, both in ER expression and in the CGRP release. Finally, we used the middle cerebral arteries (MCA) as a proxy for the TVS measuring functional difference between male and female response to estrogen.

\section{Material and methods}

\section{Animal experiments}

Adult male and female rats were anesthetized by $\mathrm{CO}_{2}$ inhalation followed by decapitation $(n=26,250-300 \mathrm{~g})$. Shortly after this, the brains (males) and the TGs (both males and females), as well as cerebral arteries were carefully dissected out and thereafter the brains were cut sagittal in the midline. The brains, the TGs and the cerebral arteries were submerged in $4 \%$ paraformaldehyde (PF) in phosphate buffered saline (PBS) buffer for $2-4 \mathrm{~h}$. Subsequently, the tissues were incubated in rising concentration of $10 \%$ and $25 \%$ of sucrose in Sorensen's phosphate buffer ( $\mathrm{pH}$ 7.2) to ensure cryo-protection. Finally, the tissues were embedded in a gelatin medium (30\% egg albumin, $3 \%$ gelatin), sectioned at $10 \mu \mathrm{m}$ (TGs and arteries) or $12 \mu \mathrm{m}$ (brains) thick slices and stored at $-20{ }^{\circ} \mathrm{C}$. The method of PF fixation allows for a proper fixation up to $2-3 \mathrm{~mm}$ from the surface of the brain and inwards [20]. Since we examine a brain volume of $1 \mathrm{~mm}$ lateral to the midline $(+0.5-+1.5 \mathrm{~mm})$, a proper fixation of the tissue used for the immunohistochemical investigation is achieved.

The 6th edition of The Rat Brain in Stereotaxic Coordinates by Paxinos and Watson [23] and hematoxylineosin (HE) staining of sagittal sections spanning over $0.5 \mathrm{~mm}$ to $1.5 \mathrm{~mm}$ lateral to the midline were used to identify the different areas of our study. The methods used in the present study are technically similar to that published earlier [24]. 


\section{Hematoxylin-eosin (HE)}

Cryo-sections of the whole brain, including cerebrum, cerebellum, brainstem and $\mathrm{C}_{1}$ spinal cord, and TGs, were stained using $\mathrm{HE}$ (Htx $4 \mathrm{~min}$, Eosin $1 \mathrm{~min}$ ). The staining was done in order to examine the morphology and condition of the tissue, and to identify the distance of the section of the brain from the midline. HE-staining of sagittal sections spanning over $0.5 \mathrm{~mm}$ to $1.5 \mathrm{~mm}$ lateral to the midline were used to identify the different areas subjected to the detailed study of the estrogen receptors ER $\alpha, E R \beta$ and GPER distribution (Fig. 1).

\section{Immunohistochemistry}

Brain, TG and cerebral arteries sections cut in a cryostat (Microm HM500M; Thermo Scientific, Walldorf, Germany) were washed in PBS containing 0.25\% Triton$\mathrm{X}$ (PBS-T) for $15 \mathrm{~min}$ followed by application of the primary antibodies (Table 1) with incubation overnight at $+4{ }^{\circ} \mathrm{C}$ in moisturized incubation chambers. The following day, the sections were rinsed twice in PBS-T for 15 min prior to incubation with secondary antibodies (Table 1 ) for $1 \mathrm{~h}$ at room temperature. Finally, the sections were washed $2 \times 15$ minutes and mounted with cover glass and Vectrashield mounting medium containing 4',6-diamidino-2-phenylindole (DAPI) (Vector Laboratories, Burlingame CA, USA). Negative controls were performed for each set by omitting the primary antibody (not shown). Any resulting immunofluorescence would suggest unspecific binding of the secondary antibodies.

For double immunohistochemistry, the procedure described above was repeated two times. The first primary antibody was matched with its appropriate secondary antibody before the second round of primary and secondary antibodies were applied and finally mounted.
Quantification of ER $\alpha, E R \beta$ and GPER immunoreactive cells was performed in male and female rats. Estimation of the prevalence ER $\alpha, E R \beta$ and GPER in the TGs were determined by counting intermingled cells in pooled ophthalmic, maxillary and mandibular areas of each ganglion [25]. We counted cells only intermingled in fibers since our experience is that neurons close to the surface may show artefactual fluorescence. All negative and immunoreactive cells were counted in each area. The mean percentage of positive neurons (small and medium sized) in 3 slides/rat from 3 male or female rats were calculated (Table 2).

The sections were examined in a light and epifluorescence microscope (Nikon 80i, Tokyo, Japan) equipped with a motor table, enabling us to get images of a whole section, and with a Nikon DS-2MV camera. Finally, images were processed using Adobe Photoshop CS3 (v0.0 Adobe Systems, Mountain View, CA).

Dura mater spreads were collected from 5 additional male rats (approx. $350 \mathrm{~g}$ ) for double immunohistochemistry. An antibody for contactin associated protein 1 (CASPR) was employed in combination with antibodies for either ER $\alpha$, ER $\beta$ or GPER to elucidate their presence in myelinated dura fibers.

\section{CGRP/PACAP release in males and females}

Adult female and male rats (12 females and 10 males, 10-12 weeks old) were purchased from Taconic (Ejby, Denmark). All these procedures are approved by the Danish Animal Experimentation Inspectorate. The protocol is described in detail elsewhere [26,27]. Rats were anaesthetized by $\mathrm{CO}_{2}$ inhalation and decapitated. The skull was cut mid-sagittal and the brain halves were carefully removed while the cranial dura was left attached to the skull, and the TG was carefully dissected out. For the

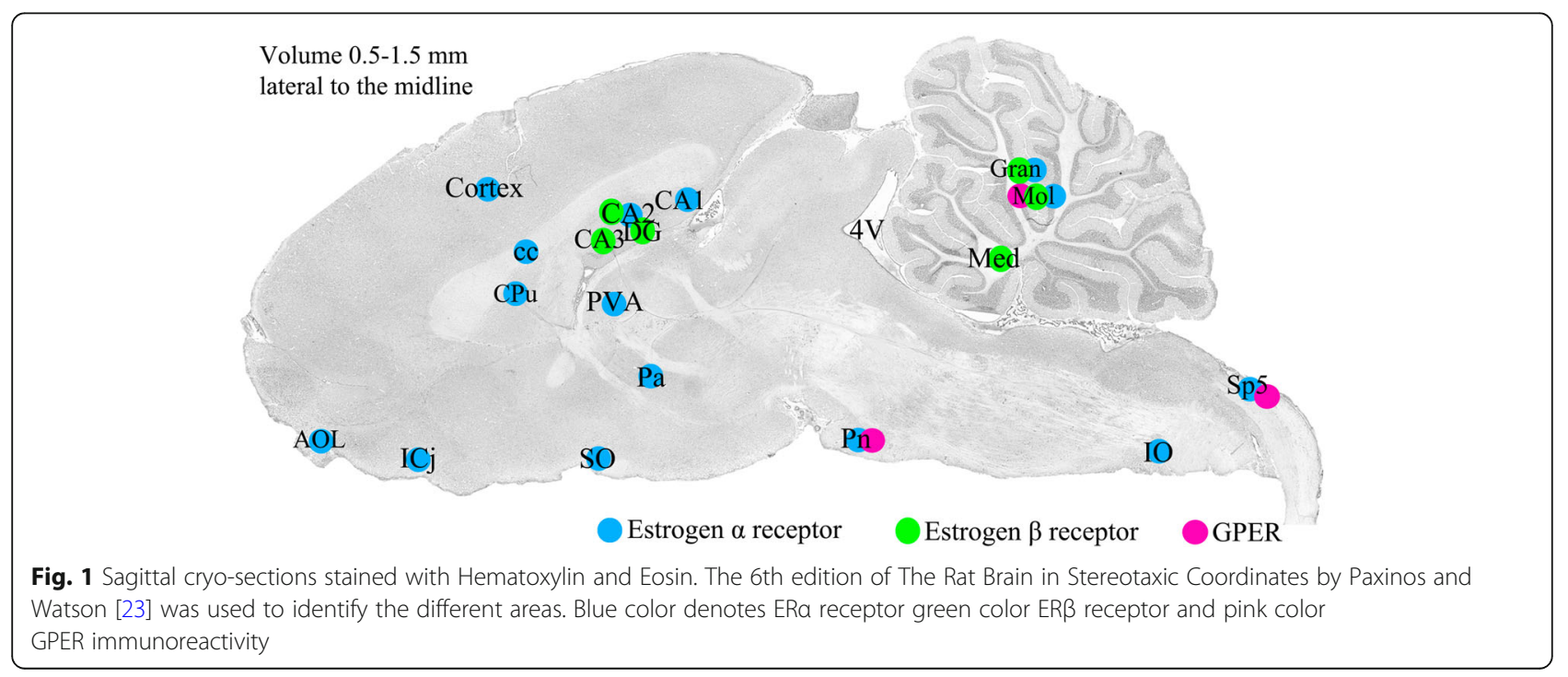


Table 1 Details of primary and secondary antibodies

\begin{tabular}{|c|c|c|c|c|}
\hline Antigen & Dilution & Species & Immunogen & Supplier \\
\hline \multicolumn{5}{|l|}{ Primary antibodies } \\
\hline CGRP (PA1-36017) & $1: 500$ & guinea pig & Synthetic human CGRP & Thermo Scientific, IL, USA \\
\hline $\begin{array}{l}\text { Estrogen Receptor a }(\mathrm{H}-184, \\
\text { sc-7207) }\end{array}$ & $1: 100$ & rabbit & Amino acids 2-185 of ER a of human origin & Santa Cruz Biotechnology, CA, USA \\
\hline Estrogen Receptor a (ab75635) & 1:100 & rabbit & $\begin{array}{l}\text { Synthetic peptide corresponding to Human Estrogen } \\
\text { Receptor alpha ( } \mathrm{N} \text { terminal). }\end{array}$ & Abcam, Cambridge, UK \\
\hline Estrogen Receptor $\beta$ (PA1-311) & $1: 100$ & rabbit & $\begin{array}{l}\text { Synthetic peptide corresponding to residues } \\
\text { A(55)EPQKSPWCEARSLEH(70) of rat ER beta }\end{array}$ & Thermo Scientific, IL, USA \\
\hline Estrogen Receptor $\beta$ (ab288) & 1:250 & rabbit & $\begin{array}{l}\text { Recombinant 6-His fusion protein encoding amino } \\
\text { acids 1-153 of human ER expressed in E.coli }\end{array}$ & Abcam, Cambridge, UK \\
\hline $\begin{array}{l}\text { GPER (G protein-coupled } \\
\text { estrogen receptor } 1 \text { ) }\end{array}$ & 1:100 & rabbit & $\begin{array}{l}\text { (C) ETFRDKLRLYAQK, corresponding to amino acid } \\
\text { residues 329-342 }\end{array}$ & Alomone Labs, Ltd., Jerusalem, Israel \\
\hline $\begin{array}{l}\text { CASPR (contactin associated } \\
\text { protein 1) }\end{array}$ & $1: 100$ & mouse & Recombinant protein corresponding to rat Caspr & $\begin{array}{l}\text { Millipore Corporation, Temecula, } \\
\text { CA, USA. }\end{array}$ \\
\hline \multicolumn{5}{|l|}{ Secondary antibodies } \\
\hline Anti-guinea pig & $1: 100$ & Alexa 488 & \multicolumn{2}{|l|}{ Thermo Scientific, IL, USA } \\
\hline Anti-guinea pig & $1: 400$ & Cy3 & \multicolumn{2}{|l|}{ Jackson Immunoresearch Laboratories, West Grove, PA, USA } \\
\hline Anti-rabbit & $1: 400$ & Cy3 & \multicolumn{2}{|l|}{ Jackson Immunoresearch Laboratories, West Grove, PA, USA } \\
\hline Anti-rabbit & $1: 100$ & Cy2 & \multicolumn{2}{|l|}{ Jackson Immunoresearch Laboratories, West Grove, PA, USA } \\
\hline Anti-mouse & $1: 400$ & Cy3 & \multicolumn{2}{|l|}{ Jackson Immunoresearch Laboratories, West Grove, PA, USA } \\
\hline
\end{tabular}

buffer system, $300 \mu \mathrm{L}$ of synthetic interstitial fluid (SIF, composition: $108 \mathrm{mM} \mathrm{NaCl}, 3.5 \mathrm{mM} \mathrm{KCl}, 3.5 \mathrm{mM}$ $\mathrm{MgSO}_{4}, 26 \mathrm{mM} \mathrm{NaHCO}, \mathrm{NaH}_{2} \mathrm{PO}_{4}, 1.5 \mathrm{mM} \mathrm{CaCl}$, 9.6 $\mathrm{mM}$ NaGluconate, $5.6 \mathrm{mM}$ glucose and $7.6 \mathrm{mM}$ sucrose; $\mathrm{pH}$ 7.4) at $+37^{\circ} \mathrm{C}$ was used. TGs were randomized, placed in Eppendorf tubes in a heating block at $+37^{\circ} \mathrm{C}$ and washed. For the skull halves, these were also randomized and placed in a humid chamber above a water bath to maintain temperature at $+37^{\circ} \mathrm{C} .200 \mu \mathrm{L}$ samples for measuring CGRP/PACAP content were collected from both tissues $10 \mathrm{~min}$ after stimuli, mixed with $50 \mu \mathrm{L}$ enzyme immunoassay buffer (containing protease inhibitors) and stored at $-20^{\circ} \mathrm{C}$ until analysis, within a week after the experiment was performed. The release of CGRP and PACAP was induced by $60 \mathrm{mM}$ potassium. To maintain equal osmolality in the $60 \mathrm{mM} \mathrm{K}^{+}$buffer, a proportional amount of $\mathrm{Na}^{+}$was removed from the buffer.

The samples $(100 \mu \mathrm{L}$ for CGRP and $100 \mu \mathrm{L}$ for PACA P) were processed using commercial EIA kits, Human CGRP ELISA KIT (SPIbio, Paris, France) to study CGRP

Table 2 Percentage of immunoreactive neurons in male and female TG

\begin{tabular}{lll}
\hline & Male & Female \\
\hline ERa & $32 \%$ & $59 \%$ \\
ERß & $34 \%$ & $72 \%$ \\
GPER & $48 \%$ & $65 \%$ \\
\hline
\end{tabular}

with a detection limit of $0.7 \mathrm{pg} / \mathrm{mL}$ and specificity for rat CGRP $-\alpha / \beta$ at $120 \%$. For PACAP release the rat PACAP ELISA Kit (LS-Bio, LS-F16956, WA, USA) with detection rate: $6.25-400 \mathrm{pg} / \mathrm{mL}$ and sensitivity: $6.25 \mathrm{pg} / \mathrm{mL}$ was used. The determination of CGRP and PACAP content was based on a standard curve which was run parallel to the experiment. The protocol was performed following the manufacturer's instructions and the optical density was measured at $410 \mathrm{~nm}$ using a micro-plate photometer (Tecan, Infinite M200, software SW Magellan v.6.3, Männedorf, Switzerland).

\section{Pressurized arteriography experiments on rat middle cerebral artery}

Male $(n=6)$ and female $(n=6)$ rats $(250-300 \mathrm{~g})$ were sacrificed by $\mathrm{CO}_{2}$ inhalation and decapitation, thereafter the brains were removed and immediately chilled in cold bicarbonate buffer solution (see Drugs, Chemicals and Solutions). Middle cerebral arteries (MCAs) were carefully dissected free from adhering tissue and cut into 1$2 \mathrm{~mm}$ cylindrical segments. Each MCA was cannulated with glass micropipettes mounted in an arteriography (Living Systems, Burlington, VT) as described earlier $[28,29]$. Bicarbonate buffer solution in the arteriography was warmed to $+37^{\circ} \mathrm{C}$ and continuously bubbled with $5 \% \mathrm{CO}_{2}$ and air, resulting in a $\mathrm{pH}$ of 7.4. A transmural pressure of $85 \mathrm{mmHg}$ was maintained by raising reservoirs connected to the micropipettes. Luminal perfusion was adjusted to $100 \mu \mathrm{L} / \mathrm{min}$ (range $80-100 \mu \mathrm{L} / \mathrm{min}$ ) by setting the two reservoirs at different heights. The 
mounted segment was magnified 600 -fold with a microscope coupled to a digital camera (Axis, Lund, Sweden) connected to a computer. Images were captured and saved at an interval of $1 / \mathrm{s}$ by a specifically generated software (Mary, Nihil KB, Lund, Sweden) as well as measuring of outer vessel diameter.

After mounting and pressurizing, during a $1 \mathrm{~h}$ equilibration period, the vessels developed a spontaneous tone. Any segment that did not develop spontaneous tone of at least $10 \%$ compared to the initial diameter was excluded. Experimental protocols were not initiated until the vessel diameter was stable over a 15 min period. Presence of functional endothelium was assessed $30 \mathrm{~min}$ later by luminal application of adenosine triphosphate (ATP), $10 \mu \mathrm{M}$. A dilation of at least $10 \%$ of the resting diameter was considered indicative of functional endothelium. Cumulative concentration-response curves were performed by luminal or abluminal application of estrogen or estrogen receptor agonists in the concentration range $10^{-8}$ to $10^{-4} \mathrm{M}$.

Substances used were $17 \beta$-estradiol (dual ER $\alpha$ and ER $\beta$ receptor agonist), propyl-pyrazole-triol (PPT, ER $\alpha$ receptor agonist), diarypropiolnitrile (DPN, ER $\beta$ receptor agonist) or equal volumes of vehicle alone (diemithylsulfoxide (DMSO) and ethanol). The vessel segments were exposed to calcium free buffer solution at the end of each experiment to allow for recalibration of the maximum relaxant capability of the MCA segment.

\section{Wire myography studies of human dura vessels}

The human middle meningeal artery (MMA) samples were obtained from patients (after written approval, mean age 58 years $(n=6)$, range $39-73$ years) undergoing neurosurgery at the Lund University Hospital, Sweden, for removal of a tumor. The vessels were from visually healthy region and immediately after removal immersed into cold Dulbecco's modified Eagle's medium (DMEM, Gibco, Invitrogen, Carlsbad, CA, USA). Upon arrival to the laboratory (about $30 \mathrm{~min}$ later), the vessel was carefully dissected, cut into segments ( $2 \mathrm{~mm}$ long) were mounted onto a wire myograph (Multi Myograph System-610 M, Danish Myo Technology, Aarhus, Denmark) [30] as previously described [31, 32]. Briefly, two tungsten wires with a diameter of $40 \mu \mathrm{m}$ (depending on vessel diameter) were threaded through the lumen of the segment. One wire was attached to the stationary support driven by a micrometer, and the other was attached to an isometric force transducer. The measured isometric forces were digitized and transferred to a computer running data acquisition software (Myodaq, Danish Myo Technology). From each vessel, the resting tension-to-internal circumference ratio was determined and set at $2 \mathrm{mN}$.
The tissue baths were filled with a bicarbonate buffer solution that was gassed with $95 \% \mathrm{O}_{2}$ and $5 \% \mathrm{CO}_{2}$ and maintained at $+37^{\circ} \mathrm{C}$. After a 30-min equilibration period, the vessels were exposed twice to buffer solution containing $60 \mathrm{mmol} / \mathrm{L} \mathrm{KCl}$ in order to validate contractile function. To study relaxant responses to agonists, a stable level of contraction was induced in each vessel segment with U46619 $\left(10^{-6} \mathrm{M}\right)$, which gave a stable contraction. Increasing concentrations of a relaxant agonist (estrogen receptor agonist) was then added in a cumulative fashion to determine a concentration-response curve. The change in contraction measured in $\mathrm{mN}$ per $\mathrm{mm}$ vessel length was expressed as percent relaxation of the force measured in the vessel at the stable level of precontraction. Sigmoidal curve fitting of concentrationresponse data was done using the computer program GraphPad Prism (GraphPad Software, San Diego, CA). $\mathrm{pEC}_{50}$ denotes the negative logarithm of the molar concentration needed to elicit half the maximum relaxation response. To study the effects of antagonists/inhibitors, these drugs were added $30 \mathrm{~min}$ prior to pre-contraction and present in the bath for the remainder of the experiment.

\section{Drugs, chemicals and solutions}

Brains and other tissues were removed and placed into ice-cold bicarbonate buffer of the following composition: $118.3 \mathrm{mM} \mathrm{NaCl}, 25 \mathrm{mM} \mathrm{NaHCO} 3,4.7 \mathrm{mM} \mathrm{KCl}, 1.2 \mathrm{mM}$ $\mathrm{MgSO}_{4}, 1.2 \mathrm{mM} \mathrm{KH_{2 }} \mathrm{PO}_{4}, 15 \mathrm{mM} \mathrm{CaCl}$ and $11.1 \mathrm{mM}$ glucose, $\mathrm{pH}$ 7.4.

Phenylephrine, carbachol and L-NAME $\left(\mathrm{N}^{\mathrm{G}}\right.$-nitro-Larginine methyl ester hydrochloride) were dissolved in distilled water to a stock solution concentration of $10^{-2}$ M. Prostaglandin $F_{2 \alpha}$, indomethacin, the agonists $17 ß$ estradiol, PPT $\left(4,4^{\prime}, 4^{\prime \prime}\right.$-(4-propyl-[1H]-pyrazole-1,3,5 -triyl)trisphenol), DPN (2,3-bis (4-hydroxyphenyl)-propionitrile), and G-1 $\left(( \pm)-1-\left[\left(3 \mathrm{a} R^{*}, 4 S^{*}, 9 \mathrm{~b} S^{*}\right)-4\right.\right.$-(6-bromo1, 3-benzodioxol-5-yl)-3a,4,5,9b-tetrahydro-3H-cyclop enta [c]quinolin-8-yl]-ethanone) and the antagonists ICI $182,780 \quad(7 \alpha, 17 \beta-[9-[(4,4,5,5,5$-pentafluoropent $\quad y l)$ sulfinyl]nonyl]estra-1,3,5(10)-triene-3,17-diol), MPP (1,3-bis (4-hydroxyphenyl)-4-methyl-5-[4-(2-piperidinylethoxy)phenol]-1H-pyrazole dihydrochloride), and G-15 ((3aS $S^{*}$, $\left.4 R^{*}, 9 \mathrm{~b} R^{*}\right)-4$-(6-Bromo-1,3-benz odioxol-5-yl)-3a,4,5,9b$3 H$-cyclopenta $[c]$ quinolone) were dissolved in DMSO to a stock solution concentration of $10^{-2} \mathrm{M}$. On the day of experiments the substances were further diluted in bicarbonate buffer solution to their final concentrations. All substances were obtained from Tocris Bioscience (Bristol, UK).

\section{Analysis and statistics}

Values are given as mean \pm S.E.M. Number of experiments $=\mathrm{n}$, which in the wire myograph experiments 
corresponds to number of vessel segments tested. In each experiment, segments were taken from a minimum of 3 animals. Statistical calculations were performed using GraphPad Prism. Data were analyzed by either paired Student's T-test, or two-way ANOVA with repeated measures and Tukey's post hoc test. $P<0.05$ was considered significant.

\section{Results}

\section{Estrogen receptors in the brain}

An overview is shown in Fig. 1. We first decided to examine the estrogen receptor expression in the brain. $\mathrm{ER} \alpha$ was found throughout the whole brain, including cerebrum, cerebellum, brainstem and $C_{1}$ spinal cord (Fig. 2). The main part of this work was done on male rats. Preliminary work has now revealed that there is a rich expression of estrogen receptors also in females; however, this work will need quantitative analysis which we aim to proceed with in future studies.

For the migraine related structures, we found ER $\alpha$ in the supraoptic nucleus $(\mathrm{SO})$ and in the paraventricular hypothalamic nucleus $(\mathrm{Pa})$, and in the nuclei of neurosecretory cells (these are oxytocin and vasopressin producing) in the hypothalamus. Further, in the ventral striatum, a region of the brain, which is part of the limbic system, the Island of Calleja ( $\mathrm{ICj}$ ), a group of neural granule cells showed intense ER $\alpha$ immunoreactivity. Immunoreactivity was also seen in the olfactory tubercle $\mathrm{(Tu}$ ). All layers of the cerebral cortex (Oc2; occipital cortex area 2) contained ER $\alpha$ immunoreactivity, except for the outer molecular layer. Pontine nuclei $(\mathrm{Pn})$ is a part of the brainstem that conducts signals from the brain down to cerebellum and medulla, and tracts that carry the sensory signals up into the thalamus. Intense
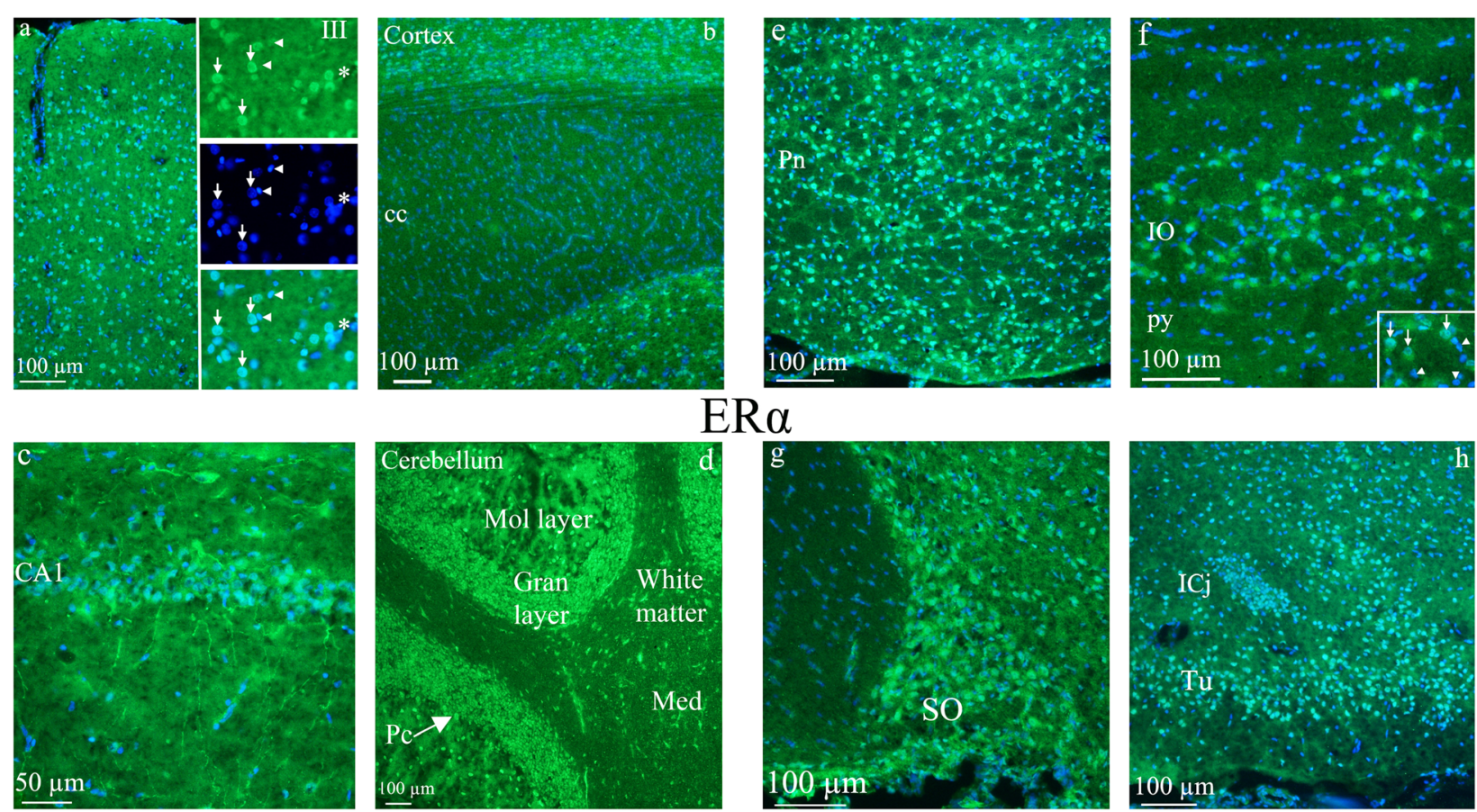

\section{$\mathrm{ER} \alpha$}
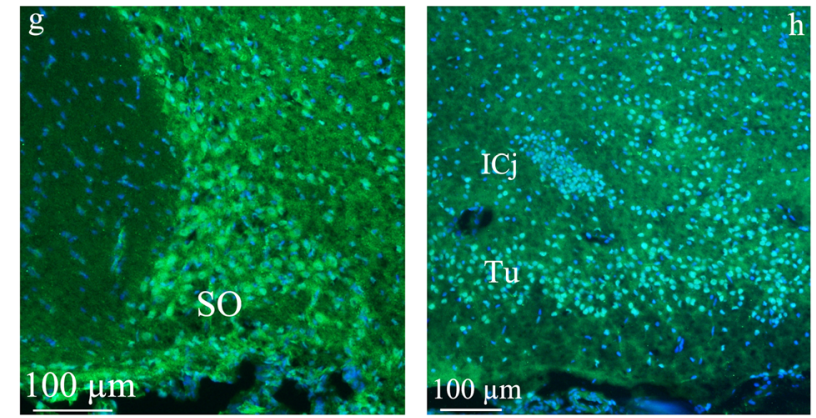

Fig. 2 ERa receptor distribution. a Cerebral occipital cortex - all layers of the cortex contained ERa immunoreactivity, except for the outer molecular layer (layer I). In the column in the middle, from the top ERa immunohistochemistry is visualized in layer III, in the middle DAPI nuclear staining and at the bottom the merged images. Arrows point at nuclei of ERa positive neurons, arrowheads at negative glial cells and asterisk at a blood vessel. b In the white matter corpus callosum (cc), very few or no ERa expressing nuclei were found. c ERa receptor distribution in the hippocampus - in the hippocampal area CA1, ERa expression in the neuronal cytoplasm and fibers were found. $\mathbf{d}$ ERa receptor distribution in the cerebellum - most nuclei expressed ERa in the cerebellum. Immunoreactivity was found in the molecular (mol layer) and granular layers (gran layer), and in the Purkinje cells (Pc). In addition, expression was observed in the Medial cerebellar nuclei (Med). e and $\mathbf{f}$ ERa receptor distribution in the Pontine nuclei $(\mathrm{Pn})$ and Inferior olive $(\mathrm{IO})$ - Pontine nuclei is a part of the brainstem that conducts signals from the brain down to the cerebellum and medulla, and tracts that carry the sensory signals up into the thalamus. Intense neuronal nuclei expression was found in the Pn. The inferior olive is a structure found in the medulla oblongata and is known to coordinate signals from the spinal cord to the cerebellum to regulate motor coordination and learning. The nuclei of $\mathrm{IO}$ showed ERa immunoreactivity. Insert: arrows point at immunoreactive neuronal cell nuclei, arrow heads point at negative glial cells. $\mathbf{g}$ and $\mathbf{h}$ ERa receptor distribution in the Supraoptic nucleus (SO) and in the Island of Calleja (ICj) in the supraoptic nucleus), a nucleus of neurosecretory cells (oxytocin and vasopressin producing) in the hypothalamus, intense ERa immunohistochemistry was observed. In the ventral striatum, a region of the brain which is part of the limbic system, the Island of Calleja, a group of neural granule cells, is situated. Here, the densely packed group of cells showed intense ERa immunoreactivity. Immunoreactivity was also seen in the olfactory tubercle (Tu) 
neuronal nuclei expression was found in Pn. The inferior olive (IO) is a structure found in the brainstem and is known to coordinate signals from the spinal cord to the cerebellum to regulate memory and learning. The nuclei of IO showed ER $\alpha$ immunoreactivity.

Generally, ER $\alpha$ expression was observed in the neuronal nuclei. In addition, ER $\alpha$ immunoreactivity was observed in the nucleus of glial cells in some areas, for example in the corpus callosum. Moreover, processes from the hippocampal pyramidal cells expressed the ER $\alpha$. Accordingly, few or no cell nuclei were found to be $E R \alpha$ immunoreactive in for example fornix, optic tract inter alia (Fig. 2).

ER $\beta$ immunoreactivity was mainly found in the hippocampus and the cerebellum. We did not observe ER $\beta$ in structures such as thalamus and hypothalamus known to be involved in migraine pathophysiology. The expression of ER $\beta$ was often observed in tiny loop-formations or short curvatures in areas close to the cell surface or intercellularly, reminiscent of extra cellular matrix distribution. Also here, the hippocampus was the only area where neuronal cell bodies expressing ER $\beta$ could be identified. In the cerebellum, the typical ER $\beta$ expression described above was found in the molecular and granular layers, but not in the Purkinje cells and not in the white matter (Fig. 3).

GPER was mainly found in the Pontine nuclei, cerebellar molecular layer and the spinal trigeminal tract (Sp5). In Pn the GPER immunoreactivity was found in the cell nuclei and less prominently in cytoplasmic and fiber structures. In the molecular layer of the cerebellum fiber structures were immunoreactive. We found GPER immunoreactive fibers in the Sp5 region, which constitutes an essential part of the pain pathways activated in migraine attacks (Fig. 4).

\section{Estrogen receptors in the trigeminal ganglion (TG)}

$\mathrm{ER} \alpha$ was found in the nuclei of most TG neurons, in the thicker neuronal fibers and in most of the satellite glial cells (SGC) of the TG (Fig. 5). Double immunohistochemistry
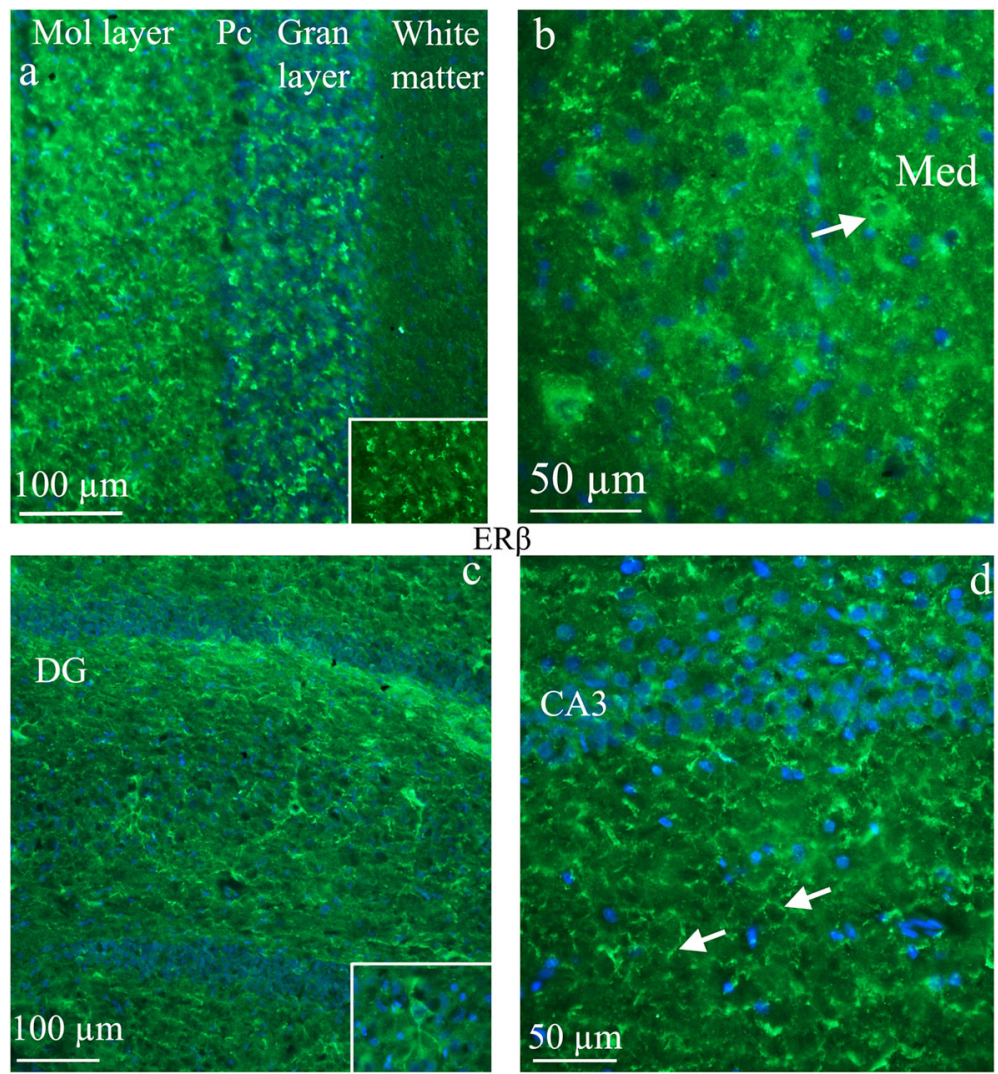

\section{西}

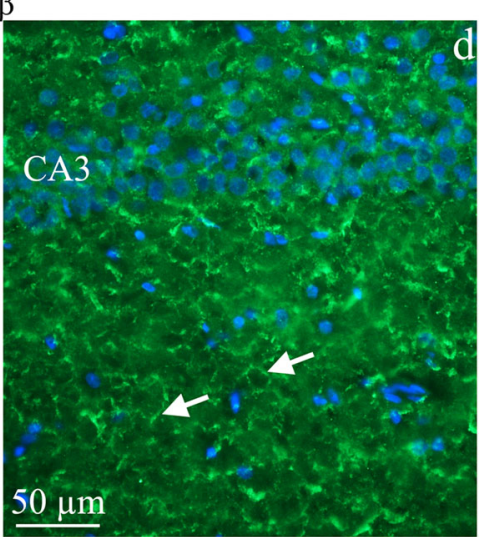

Fig. 3 ER $\beta$ receptor distribution. $\mathbf{a}$ and $\mathbf{b}$ ) ER $\beta$ receptor distribution in the cerebellum - the expression of ER $\beta$ was often observed in tiny loopformations or short curvatures in areas close to the cell surface or intercellularly, reminiscent of extra cellular matrix distribution. In the cerebellum, the typical ERß expression was found in the molecular (mol layer) and granular (gran layer) layers, but not in the Purkinje cells (PC) and not in the white matter. Insert: staining of the granular layer. In Medial cerebellar nuclei (Med), occasional neuronal expression was observed (arrow). c and d) ERß receptor distribution in the hippocampus - the dentate gyrus (DG) and CA3 are parts of hippocampus. Some ER $\beta$ positive pyramidal cells were found in DG (insert). In the other parts of hippocampus, staining resembling cell surface or extracellular matrix immunoreactivity was observed (arrows) 

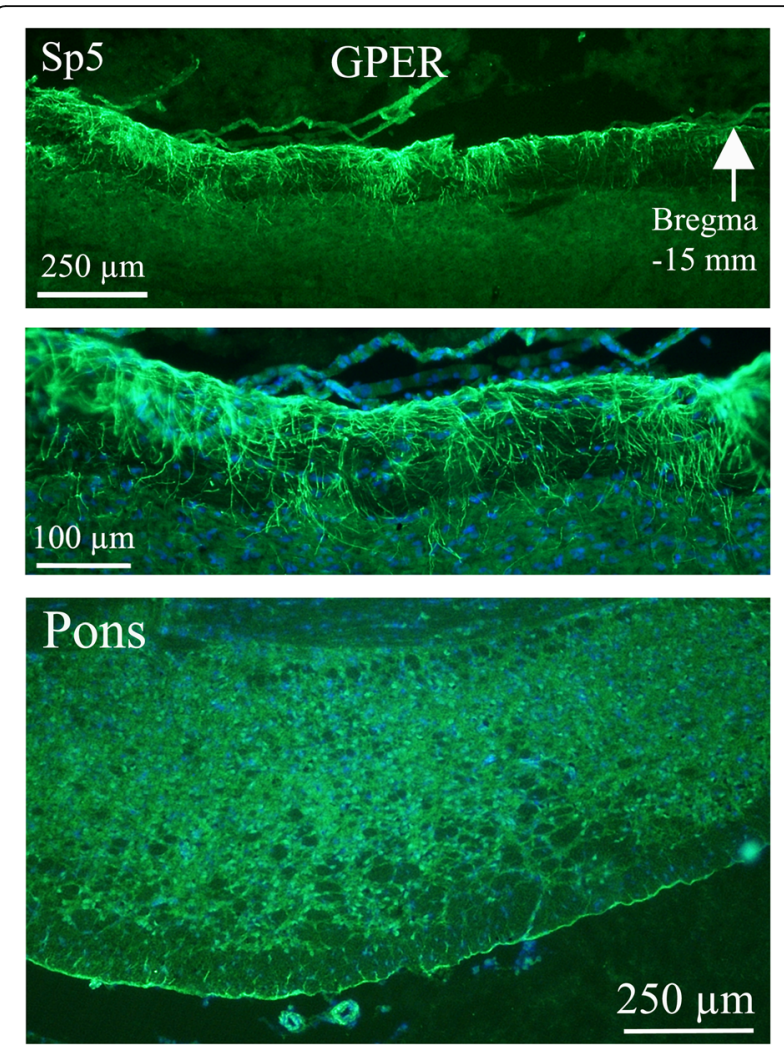

Fig. 4 GPER receptor distribution in the Sp5 and Pontine nuclei. GPER was mainly found in the Pontine nuclei, cerebellar molecular layer and the spinal trigeminal tract. The spinal trigeminal tract region (Sp5) constitutes an essential part of the pain pathways activated in migraine attacks. We found GPER immunoreactive fibers in the Sp5 region. In Pontine nuclei the GPER immunoreactivity was mainly found in the cell nuclei, but some cytoplasmatic and fiber staining were also found with ER $\alpha$ (nuclei staining) and CGRP (cytoplasmic staining) showed that the ER $\alpha$ is expressed in cells that co-express CGRP (Fig. 6a). Double immunohistochemistry with ER $\alpha$ (nuclei staining) and RAMP1 (mainly expressed in medium sized cells and thick fibers, consistent with myelinated $A \delta$ sensory fibers [33]), revealed that some cells expressed both ER $\alpha$ and RAMP1 (Fig. 6b). We have recently demonstrated the expression of the paranodal marker contactinassociated protein 1 (CASPR) in the paranodal areas of the different myelinated fibers inhabiting the TG and the dura mater [33]. We found ER $\alpha$ in the fibers that also expressed CASPR (paranodal region flanking the of nodes of Ranvier) (Fig. 6c).

ER $\beta$ was found in the cytoplasm of trigeminal neurons. The staining pattern resembles that of the Golgi apparatus (Fig. 7a and b). Furthermore, using ER $\beta$ and CGRP antibodies it was shown that ER $\beta$ and CGRP appeared to be expressed in the same organelle (Golgi apparatus) (Fig. 7b). Expression of GPER was observed in the cell membrane and cytoplasm in most neurons (Fig. 8). Double immunohistochemistry with GPER and CGRP showed that most CGRP positive cells also expressed GPER. ER $\alpha$ and ER $\beta$ immunohistochemistry of cerebral arteries revealed that both ER $\alpha$ and ER $\beta$ expression was found in the smooth muscle cells and the endothelial cells (Fig. 9). Spread preparations revealed CASPR positive $A \delta$-fibers in the dura mater. However, no immunopositivity for ER $\alpha, E R \beta$ or GPER was detected in these dura fibers (data not shown).

\section{Comparison of estrogen receptors in the trigeminal ganglion}

We then compared the trigeminal ganglion from males and females. The numbers of immunoreactive neurons in male and female TG were calculated and more than 450 neurons were counted in each group (Fig. 10). 32\% of the male and $59 \%$ of the female neurons expressed
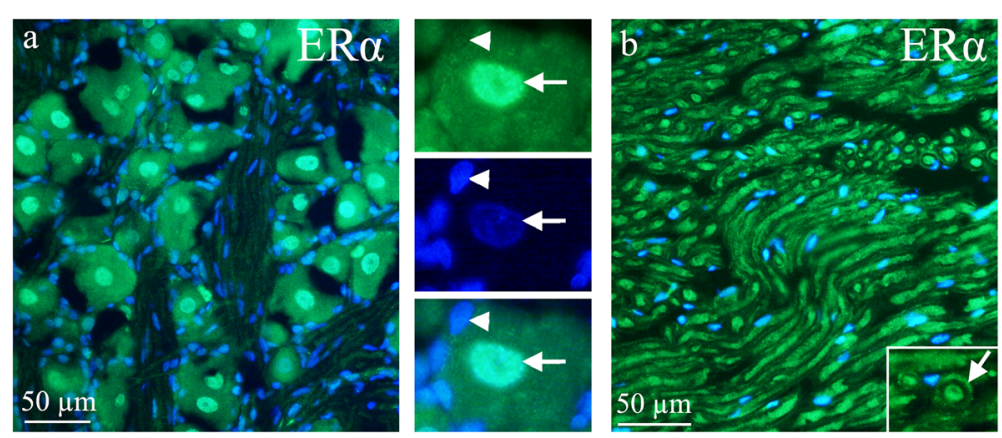

Fig. 5 ERa receptor distribution in the TG. a The neuronal nuclei of the TG express ERa receptor. The montage discloses the neuronal nuclei staining, arrow heads point at a negative nucleus of the glial cells, and arrows at a positive neuronal nucleus. $\mathbf{b}$ In the trigeminal nerve, immunoreactivity was found in the nerve fibers. Insert: Perpendicular cut nerve fibers displays an inner immunoreactive fiber (arrow). Outside of the fiber, the myelin sheet showed no immunoreactivity 


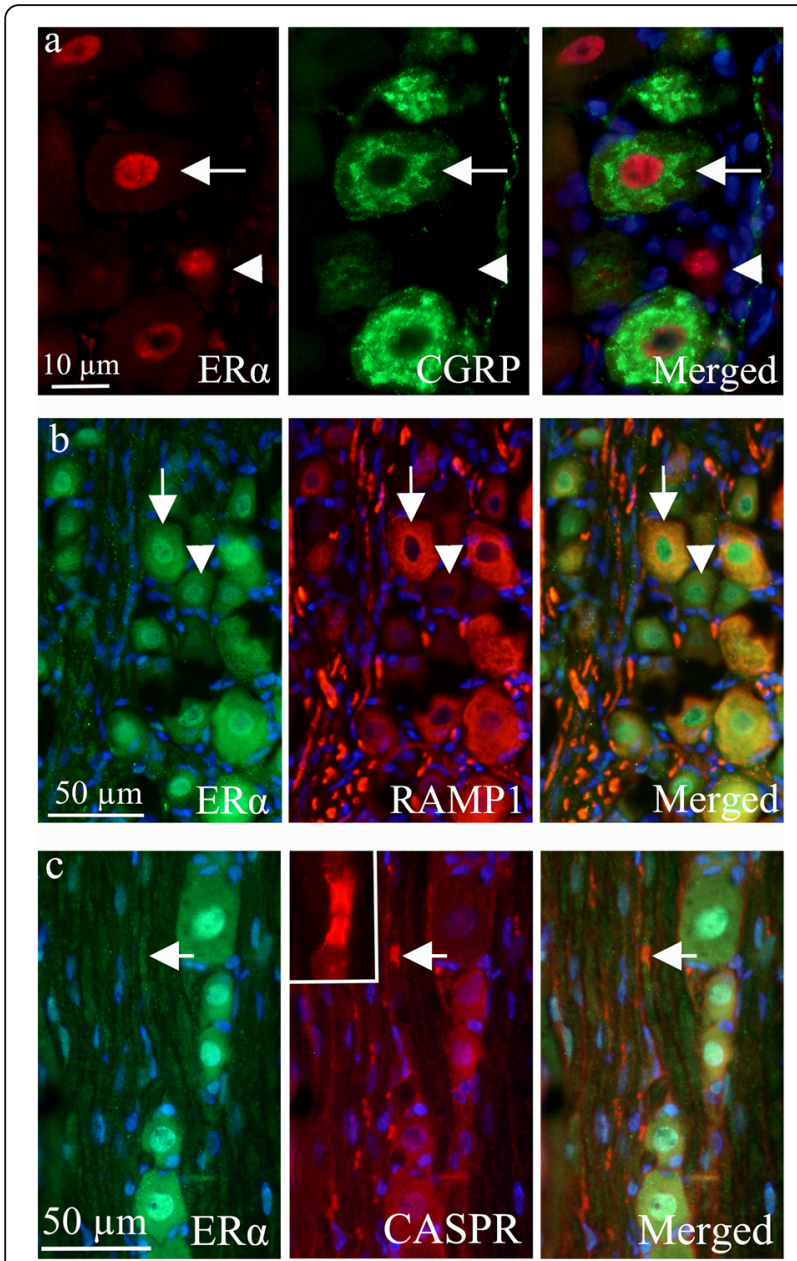

Fig. 6 ERa receptor distribution in the TG. a Double

immunohistochemistry of ERa and CGRP. To the left, the image shows ERa receptor expression in the nucleus of neurons (red). Arrow and arrowhead point at ERa immunoreactive neuronal nuclei. CGRP immunoreactive cells are shown in the middle panel (green). CGRP immunoreactivity was observed in the cytoplasm in a Golgi apparatus pattern. Arrow points at a CGRP immunoreactive neuron and arrowhead at a negative neuron. To the right, the merged image is shown. Arrow points at a neuron positive for both ERa and CGRP, but with immunoreactivity in different compartments of the cell. Arrowhead points at a ERa positive, but CGRP negative cells. $\mathbf{b}$ Double immunohistochemistry of ERa and RAMP1. Double immunohistochemistry with ERa (nuclei staining, arrow and arrowhead) and RAMP1 (mainly expression in medium sized cells and thick fibers, arrow points at a RAMP1 positive and arrowhead at a RAMP1 negative cell) showed that some cells expressed both ERa and RAMP1 (arrow). Fibers expressed RAMP1, but only weak ERa expression. c Double immunohistochemistry of ERa and CASPR. Double immunoreactivity of the paranodal marker contactinassociated protein 1 (CASPR) in the paranodal areas and ERa was found (arrow). Insert: paranodal area of the Ranviers node visualized by CASPR antibodies
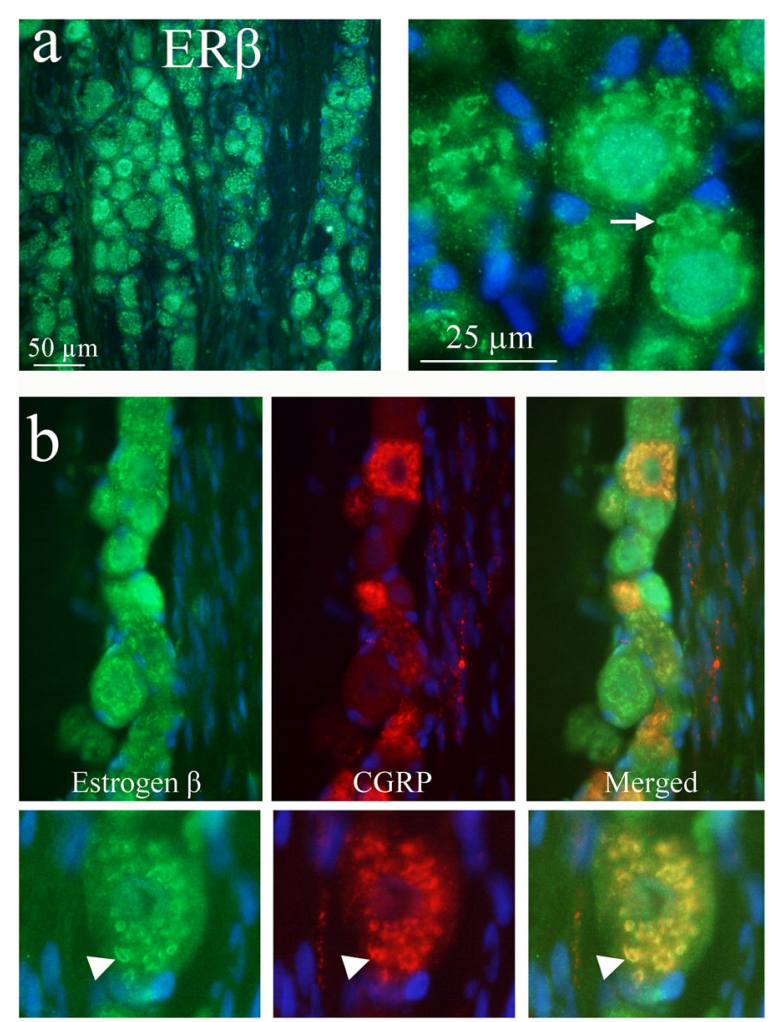

Fig. 7 ER $\beta$ receptor distribution in the TG. a ERß expression is found in the cytoplasm of most neurons. In the higher magnification to the right, arrow points at an ER $\beta$ immunoreactive neuron. $\mathbf{b}$ Double immunohistochemistry with ERß and CGRP antibodies revealed in higher magnification that both ER $\beta$ and CGRP expression is found in the same organelle, possibly the Golgi apparatus (arrow heads)

ER $\alpha$ ( $P=0.0196$, Fig. $10 \mathrm{a}), 34 \%$ of the male and $72 \%$ of the female neurons expressed ER $\beta,(P=0.0129$, Fig. 10b). $48 \%$ of the male and $65 \%$ of the female neurons expressed GPER ( $P=0.08$, Fig. 10c).

\section{Release of CGRP and PACAP from dura mater and TG in males and females}

To investigate a potential effect of endogenous estrogen we started out comparing CGRP release from males and females. For CGRP release (by exposure to potassium $60 \mathrm{mM}$ ) from the dura mater and the TG we observed a clear and significant release of CGRP but there were not any differences between sexes (Fig. 11a). There was no significant PACAP release from the dura mater from either sex. For the TG we observed significant release of PACAP from male TG $(P=0.0457, n=12)$, but only a tendency in the female group $(P=0.1355, n=10)$. For the CGRP release there were no differences between the sexes, and there was a strong release from both the dura mater and the TG preparations $(P<0.001$ for both). We further separated the data from the females into two groups, based on the state of their estrous cycle 

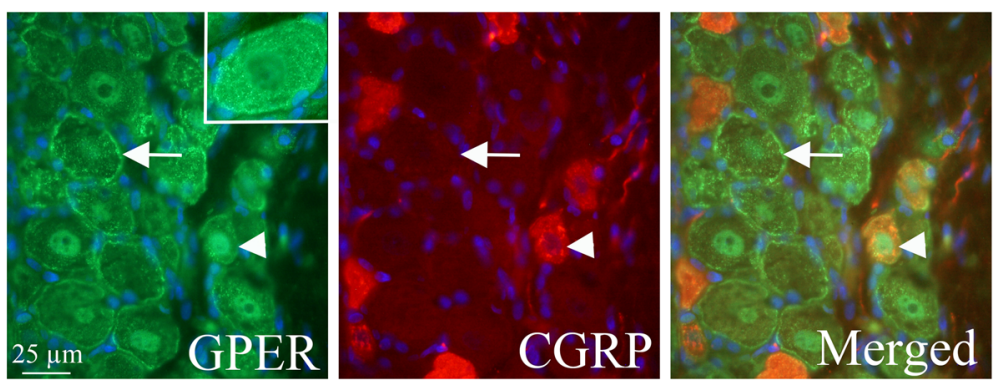

Fig. 8 GPER and CGRP distribution in the TG. Expression of GPER was observed in the cell membrane and cytoplasm in most neurons (arrow and arrowhead). Double immunohistochemistry with GPER and CGRP showed that most CGRP positive cells (arrowhead) also expressed GPER in the cytoplasm. Insert: higher magnification of a GPER positive cell, showing immunoreactivity in the cytoplasm and cell membrane

(Fig. 11b). Represented photomicrographs from the vaginal smears are shown in Fig. 11c. The only observable difference was the baseline CGRP release which was higher in rats which were in the pro-estrous state as compared to the estrous state $(P=0.0475)$.

\section{Comparison of pressurized arteriography experiments on rat middle cerebral artery}

The pressurized arteriography experiments were carried out on male and female middle cerebral arteries (MCA). After a resting period in the tissue bath the vessels
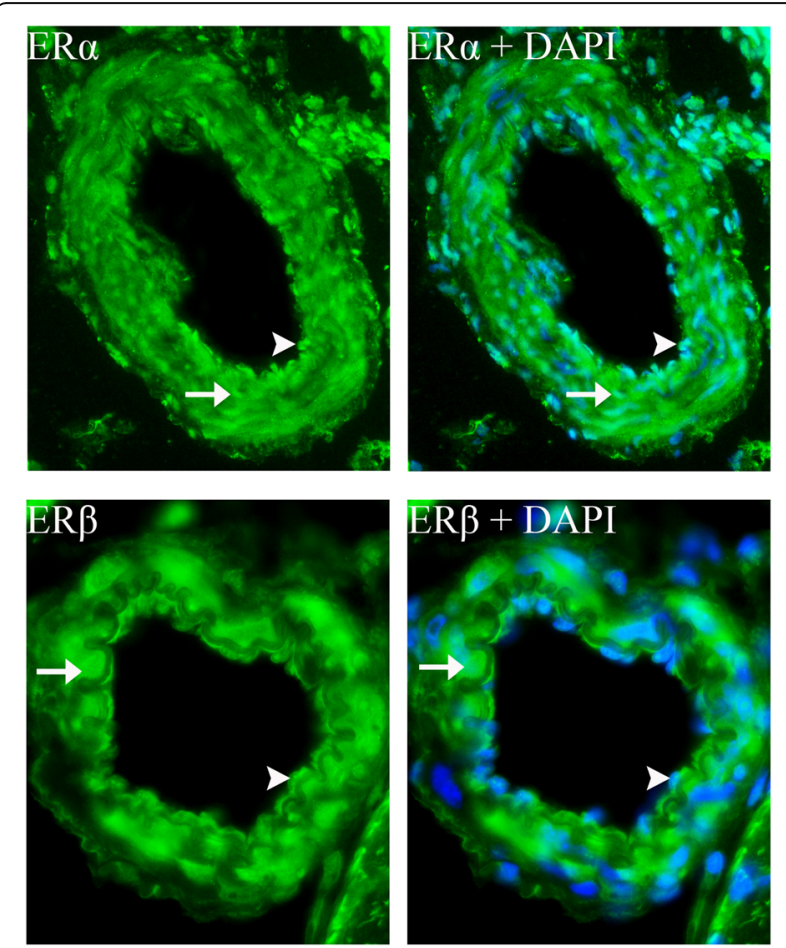

Fig. 9 ERa and ERß distribution in cerebral arteries. ERa and ERß immunohistochemistry of cerebral arteries revealed that both ERa and ER $\beta$ expression was found in the smooth muscle cells (arrow) and the endothelial cells (arrowhead) attained a stable tone and tests with ATP elicited a relaxation indicative of functional endothelium [34]. The vehicles used (low dose of $\mathrm{EtOH}$ or DMSO) did not elicit any marked dilatory effects on the tone in concentrations equivalent to the doses used in the arteriography experiments (Fig. 12a). GPER was not tested as it has been shown not to contribute significantly to relaxant responses in the MCA [35].

The endogenous ligand for the two estrogen receptors (ER $\alpha$ and ER $\beta)$, estradiol (17- $\beta$-estradiol), resulted in a marked vasodilation of the MCA when given abluminal in both male $57 \pm 17 \%$ and female $59 \pm 13 \%$ experiments $(P<0.05$, Fig. $12 \mathrm{~b})$. The luminal $\max$ vasodilation was much lower (male $16 \pm 12 \%$ and female $13 \pm 4 \% ; P<0.05$ ). There were no differences between male and female.

We went further in order to examine involved receptor subtypes. Concentration-dependent responses to propylpyrazoletriol (PPT), a specific agonist for ER $\alpha$, gave a strong relaxation of MCA when given abluminal in both male $79 \pm 4 \%$ and female $85 \pm 6 \%$ with no significant difference (Fig. 12c). For the luminal application there was a minor significant difference in the dilation $(6 \pm 5 \%$ for male and for female $26 \pm 6 \%, P<0.05)$. When given luminal only a small relaxation was seen in both male $16 \pm 7 \%$ and female $6 \pm 8 \%$ rat MCAs. For the ER $\beta$, we performed concentration-dependent responses to diarylpropionitrile (DPN). It showed no or very little relaxation in males $16 \pm 7 \%$, but a large dilation in females $109 \pm 17 \%(P<0.01)$, when given abluminal (Fig. 12d). When given luminal, there was no relaxation observed for neither males $(2 \pm 9 \%)$ nor females $(-4 \pm 7 \%)$. Hence, there appears to be vasodilatory ER $\beta$ only in female arteries. Immunohistochemistry revealed the presence of ER $\alpha$ and ER $\beta$ in the vascular smooth muscle cells (Fig. 9).

\section{Wire myography on human middle meningeal arteries}

Since the human middle meningeal artery (MMA; a dural artery) is much larger, we opted for the wire myograph. It must be noted that in this myograph both luminal and abluminal sides are exposed to the agonists. 


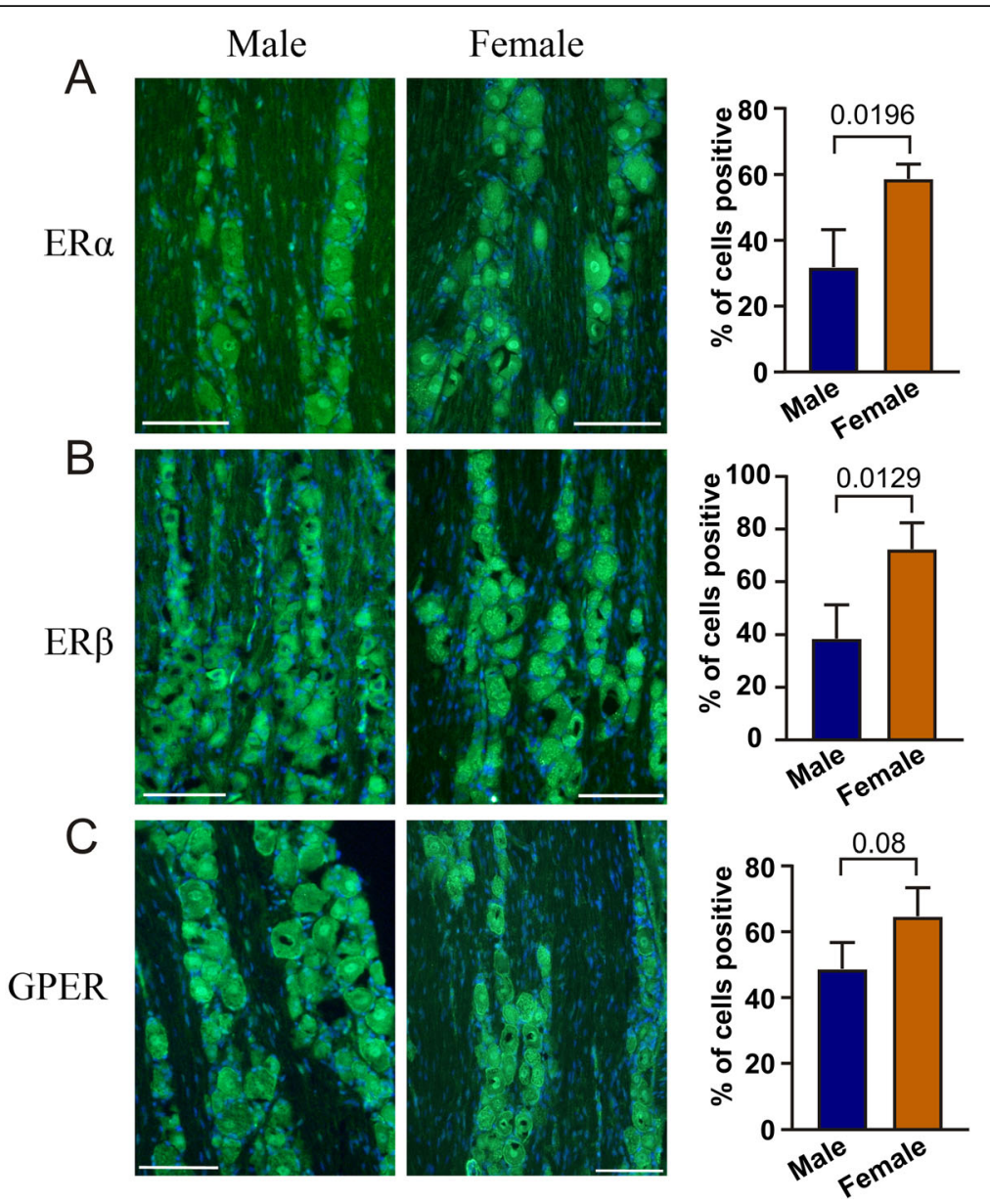

Fig. 10 Comparison of the expression of estrogen receptors in males and females. The numbers of immunoreactive neurons in male and female TG were calculated in more than 450 neurons. The data show the distribution in males and females of ERa, ERß and GPER. Data are shown as mean \pm SEM or their individual data points with pairing, and with $p$ values obtained with Student's T-test being depicted in the graph

We had arteries from 6 female patients (age avg. 58 years, range 39-73 years of age) which was found the most relevant for the current study. In addition, we blocked the endothelium responses with L-NAME, indomethacin, apamin and charybdotoxin [36, 37]. For the human MMA we observed a strong dilation (Fig. 13a) in response to 17 - $\beta$-estradiol $(88 \pm 17 \%)$, which was unaffected by blocking the endothelium derived factors $(101 \pm 32 \%)$. The specific ER $\alpha$ agonist, PPT (Fig. 13b), showed a modest dilation of $(46 \pm 12 \%)$, which was not affected by blocking the endothelium $(37 \pm 10 \%)$. In the human arteries, it appears that ER $\beta$ (Fig. 13c) is the main receptor causing the dilation $(124 \pm 8 \%)$. The response is unaffected by blocking the endothelium (142 $\pm 42 \%)$ when tested in the presence of L-NAME, indomethacin, apamin and charybdotoxin (blocking NOS, prostacyclin and endothelium derived hyperpolarizing factor), suggesting a receptor linked to the vascular smooth muscle cells.

\section{Discussion}

This study is the first to comprehensively analyze various aspects of the estrogen receptors in relation to migraine related structures in the brain and in the TVS. We revealed a wide distribution of estrogen receptors in the CNS and in TVS. The data showed significantly more expression of ER $\alpha$ and ER $\beta$ in the female trigeminal ganglion compared to males. The data indicate that there are minor differences in the level of induced CGRP and PACAP release between males and females. The ER receptor agonists revealed dilation both to estrogen and to more specific agonists, with some minor difference related to ER $\alpha$ and a larger significant difference in the dilation in response to the ER $\beta$ agonist. This suggests that the effect of estrogen might be linked both to neuronal modulation and to direct vascular effects in intracranial vessels.

In addition to the well-known responses to estrogens in the female reproductive system, it can act in the brain 


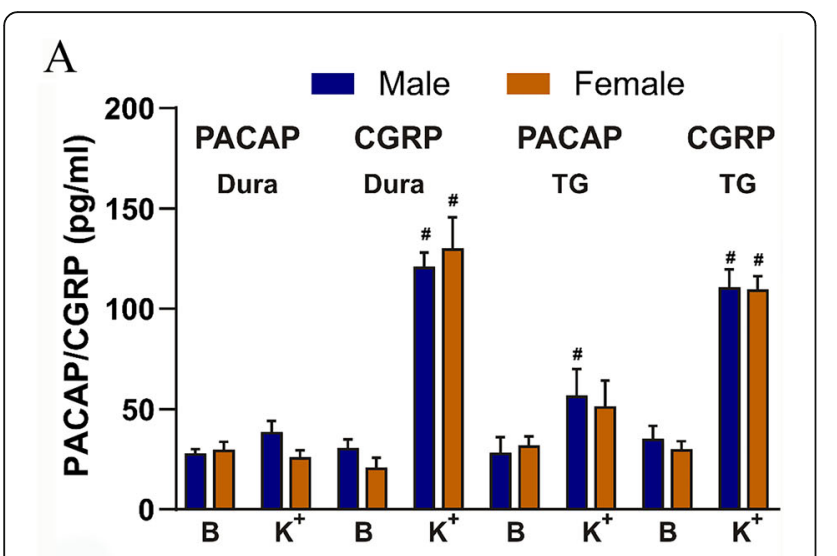

B

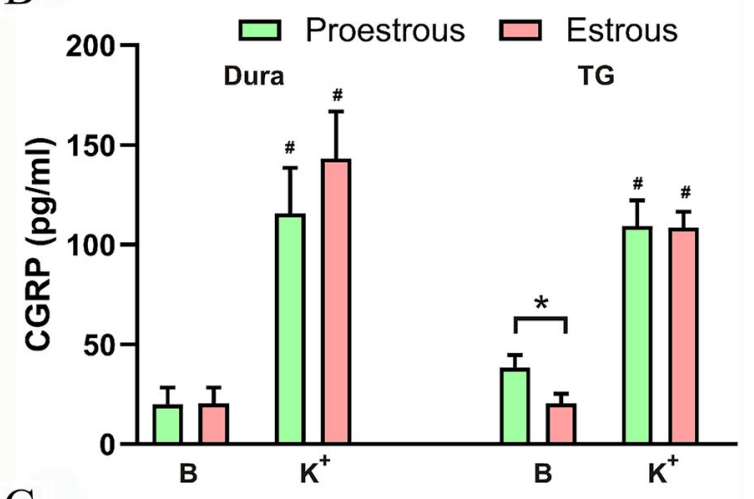

C

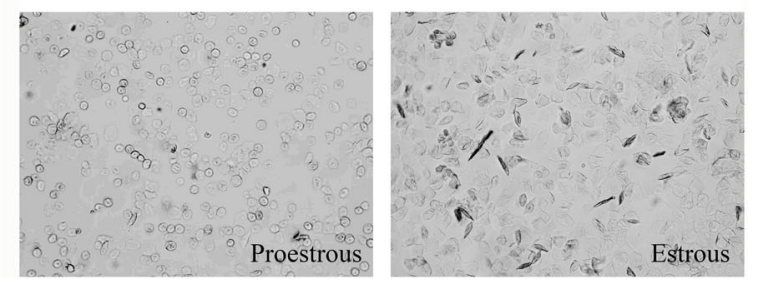

Fig. 11 Comparison of in situ CGRP and PACAP release from the dura and trigeminal ganglion. a The addition of $60 \mathrm{mM} \mathrm{KCl}(\mathrm{K}+)$ caused no PACAP release from the dura but a significant release was seen from the TG in males $(n=12)$ but not in females $(N=10)$. CGRP release was much stronger both from the dura and the TG. $\mathbf{b}$ there were no significant differences in the CGRP releases in the dura or $\mathrm{TG}$, however a significant lower baseline was observed in females in estrous. c Representative samples of the vaginal smears from the female rats, used to determine the cycle-stage. Data are shown as mean \pm SEM or their individual data points with pairing, and with $p$ values obtained with Student's T-test being depicted in the graph. ${ }^{*}=p<0.05$ between groups, and $\#=p<0.05$ from baseline

to regulate a wide range of behaviors and physiological functions in both sexes [38]. Traditionally, the actions of circulating estrogen is believed to be mediated mainly by binding to two specific receptors, ER $\alpha$ and ER $\beta$, which recognize and activate gene transcription through binding to genomic elements [38]. In this study we demonstrate using immunohistochemistry ER $\alpha, E R \beta$ and GPER expression in the rat brain and TG. We show using two different $\mathrm{ER} \alpha$ antibodies that $\mathrm{ER} \alpha$ is mainly expressed in the cell nucleus. By using two different ER $\beta$ antibodies we demonstrate that ER $\beta$ is mainly observed in tiny loop-formations or short curvatures in areas close to the cell surface in the CNS, but in TG the ER $\beta$ expression was observed in the cytoplasm, resembling the Golgi apparatus. GPER was expressed in a few areas in the brain, e.g. the Pontine nuclei and Sp5 (trigeminal nucleus caudalis), but in the TG almost all neurons expressed GPER on the cell surface and in the cytoplasm. In general, the data suggest that circulating estrogen might have dynamic influences on the function of the TVS and in the CNS.

Previous work, reviewed by Rossetti and coworkers [39], have shown that many cells with ER $\alpha$ expression are found in the bed nucleus of the stria terminalis (BST), amygdala, preoptic area and various other hypothalamic nuclei. High levels of expression are seen in olfactory regions, midbrain and cerebellum. Similar to $E R \alpha, E R \beta$ is seen in the BST, amygdala, the trigeminal nuclei, the preoptic region, and other hypothalamic nuclei. In addition, ER $\beta$ is observed in some regions with low or no ER $\alpha$, e.g. supraoptic area and paraventricular nucleus. GPER is highly expressed in the olfactory bulbs, hypothalamus, cerebral occipital cortex, hippocampus and cerebellum [39]. In the present study, we observed $E R \alpha$ expression throughout the whole brain, including cerebrum, cerebellum, brainstem and $C_{1}$ spinal cord. ER $\beta$ was mainly found in the hippocampus and the cerebellum, and GPER mainly in the Pontine nuclei and Sp5. From our immunohistochemical work we agree with previous scattered studies and add a more global picture. The study includes all three estrogen receptors and add the focus to areas involved in different primary headache syndromes, putatively adding aspects to the gender imbalance in migraine prevalence (Fig. 1).

Many studies clearly indicate that ovarian hormones can alter neurotransmitter systems that play an important role in the pathogenesis of migraine headache [40]. Female sex hormones have long been considered to play a role in migraine $[41,42]$. The different stages in a woman's life where changes in female hormone levels occur (such as puberty, pregnancy, and menopause) are commonly coupled with concurrent changes in migraine frequency and severity [43, 44]. The beginning of sex hormone secretion and ending with loss of sex hormone sensitivity could frame the migraine process that is driven by sex hormones [45]. In support, we demonstrate in the present study that the numbers of ER $\alpha$ and ER $\beta$ expressing cells are significantly higher in female TG compared to male TG (Fig. 10).

Estrogen receptors were expressed in the same neurons as both CGRP and CGRP receptors (Fig. 6). This strengthens the hypothesis that sex hormone may 

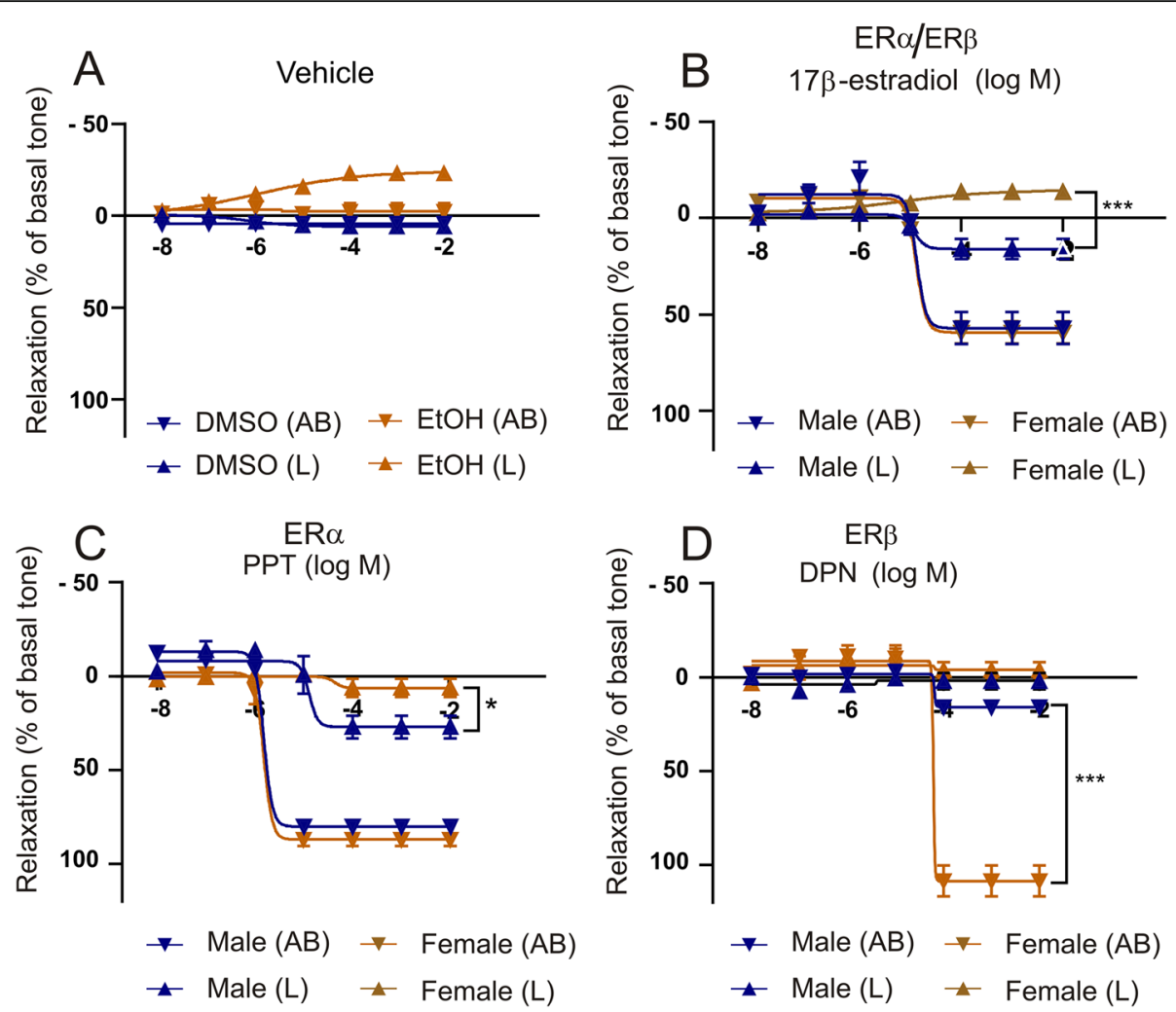

Fig. 12 Myograph response to ERa and ERß ligands on the male and female MCA. Isolated segments of rat middle cerebral artery (MCA), in the myograph. The data are shown as dilation from the myogenic tone. Cumulative concentration-response curves are shown for vehicle (a), 17ßestrogen (b), PPT (c) or DPN (d) added luminally (L) or abluminally (AB). Data points represent means \pm SEM. Significance was determined by two-way ANOVA, $n=6 .{ }^{*} p<0.05,{ }^{* *} p<0.005,{ }^{* * *} p<0.001$

modulate the CGRP system and be a key player in migraine pathophysiology [12]. For example, Wang observed that CGRP in the PAG can be modified by sex hormones [46]. Furthermore, we saw no differences in the CGRP release between males and females, this is supported by Cetinkaya et al. [47] who observed that $17 \beta$-estradiol added acutely had no effects in female peripheral terminals of meningeal trigeminal nerve or from the TG samples (compared to their controls). They did observe a minor difference in males, which might warrant future attention. Interestingly, the only difference we observed (Fig. 11) was a lower baseline in rats that are in the estrous part of the cycle. We can only speculate that CGRP might have been released during the drop in estrogen, leaving lower baseline levels. This would match the current view/hypothesis that it is the drop of estrogen that triggers migraine attack onset. PACAP release has been recently studied in detail [26], and the present study adds to the conclusion on the absence of any major difference between males and females.

Ovarian hormones passively diffuse through the bloodbrain barrier [48]. Several regions in the brain, such as cortex, thalamus, amygdala, hypothalamus, pons, cerebellar deep nuclei, vestibular nucleus and $\mathrm{Sp} 5$, are thought to be involved in migraine based on human imaging studies and known pain pathways [49]. Migraine is commonly triggered during decline in estrogen levels before and during menstruation. Many studies have now shown that women experience an unequal amount of pain and, in addition, estrogen may be an influential factor [50, 51]. Substantial clinical evidence suggests that changes in ovarian hormones affect migraine headache [40]. The current data suggest that activation of estrogen receptors in the TG could be linked to migraine pathology. Females do not only have more cells with estrogen receptors, but appear to have stronger responses as well, using the MCA as a proxy of TVS activation. Preliminary evidence would suggest that a" threshold effect" may be the most relevant mechanism through which ovarian hormones modulate migraine headache [40]. It is very interesting that ER $\alpha$ is expressed in the myelinated fibers (Fig. 5), and does exist in the nodes of Ranvier (Fig. 6), which we have previously hypothesized could be a key region for modulation of migraine pain [33].

In myograph work we observed that the relaxant responses to the estrogen receptor agonists were unaffected by administration of a cocktail of endothelium relaxing factor blockers. This suggested that the main 


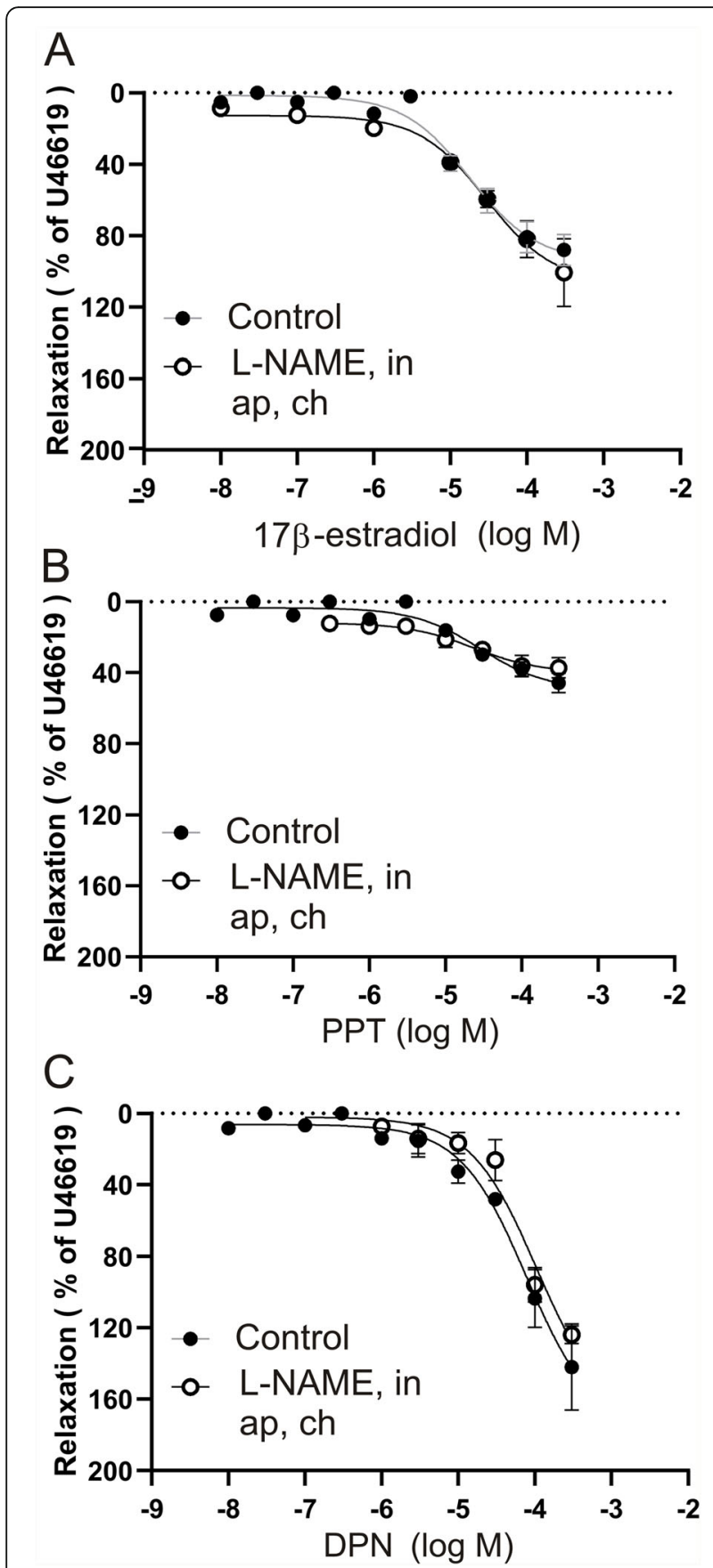

Fig. 13 Myograph response to ERa and ERß ligands on the human female dural vessel. Isolated segments of human female dural artery in the wire myograph. The data are shown as dilation from a preconstriction of U46619. To inhibit the endothelium L-NAME, indomethacin, apamin and charybdotoxin, where added. Cumulative concentration-response curves are shown for 17ß-estrogen (a), PPT (b) or DPN (c). Data points represent means \pm SEM. Significance was determined by two-way ANOVA, $n=6 .{ }^{*} p<0.05,{ }^{* *} p<0.005$, ${ }^{* * *} p<0.001$ part of the estrogen receptor agonists act via the vascular smooth muscle. In support, studies with the perfusion system (selective administration of the agonists either luminal or abluminal) showed that the ER agonists had large relaxant effects given abluminal and only minor when given luminally. The abluminal application of the ER $\alpha$ agonist PPT showed the strongest effect followed by the mixed agonist $17-\beta$-estradiol and less effect by DPN (ER $\beta$ ) agonist in males (Fig. 12). These findings are in agreement with results from Patkar et al. [35]. Interestingly, in females DPN gave a significantly larger dilatory response than what was seen in males. When applied luminal, the responses were generally weak. Thus, the findings suggest that the ER $\alpha$ receptor predominates, with an additional effect of ER $\beta$ in the female MCA. This is similar to what has been shown for the rat tail artery [52]. We have similar observation for the human MMA experiments (Fig. 13), although with a smaller contribution of ER $\alpha$, compared to the rat MCA data. Further, applying inhibitors of endothelium derived relaxing factors, showed that the effects are direct on the vascular smooth muscle cells, which confirms previous rat studies [35]. The immunohistochemical experiments of the ER expression agrees with the functional data, the ER expression is most obvious in the vascular smooth muscle cell layer (Fig. 9).

\section{Conclusion}

Clearly there are numerous expression sites for estrogen receptors both in CNS and in the TVS system, all of these sites share a relation to migraine pathophysiology. We did not find a significant difference in the CGRP or PACAP release in males and females. The most striking difference is in the amount of ER $\alpha$ and ER $\beta$ positive cells in the female TG as compared to males. We further show that the female MCA response to ER $\beta$ in a stronger fashion that for the male counterpart while the ER $\alpha$ responses were similar. Together, this points to a hypothesis where estrogen could have a modulatory role on the trigeminal neuron function in general, as well as on intracranial vasodilation, rather than on the acute CGRP release mechanisms.

\footnotetext{
Abbreviations

AOL: Anterior olfactory nucleus; CA1: Field CA1 of the hippocampus; CA3: Field CA2 of the hippocampus; CA3: Field CA3 of the hippocampus; Cb: Cerebellum; Cc: Corpus callosum; CPu: Striatum; DG: Dentate gyrus; Gran layer: Cerebellar granular layer; GPER: G-protein Coupled Estrogen Receptor; ICj: Islands of Calleja; IO: Inferior olive; Med: Medial cerebellar nu; Mol layer: Cerebellar molecular layer; PVA: Paraventricular thalamic nu; Pa: Paraventricular hypothalamic nu; Pn: Pontine nuclei; SO: Supraoptic nu; Sp5: Spinal trigeminal nu; TG: Trigeminal Ganglion
} 


\section{Authors' contributions}

$\mathrm{KW}, \mathrm{DNK}$, LE and KAH designed the study; KW, AM, JCAE, and KAH performed experiments; LE provided tools and reagents; KW, DNK, AM, JCAE, LE and KAH analyzed the data; KW, DNK, LE and KAH wrote the manuscript; AM and JCAE made further critical manuscript revisions. All authors read and commented on the final manuscript.

\section{Funding}

This work was supported by the Lundbeck foundation, Lundbeck Grant of excellence [no. R59-A5404], the Swedish Medical Research Council, and a research grant from the International Headache Society $(\mathrm{KAH})$. The funders had no role in study design, data collection and analysis, decision to publish, or preparation of the manuscript. Open Access funding provided by Lund University.

\section{Availability of data and materials}

The datasets generated during and/or analyzed during the current study are available from the corresponding author on reasonable request.

\section{Ethics approval and consent to participate}

The animal part of the study followed the guidelines of the European Communities Council (86/609/ECC) and was approved by the Regional Ethical Committee on Animal Research, Malmö/Lund, Sweden (M43-07) and by an auspices of the Swedish Department of Agriculture (M8-09, M126-12) and the Danish Animal Experimentation Inspectorate. All animal experiments were therefore performed in accordance with the European Community Council Directive on 'The Protection of Animals Used for Scientific Purposes' (2010/63/EU). The human part of the study was approved by the Regional Ethics Review Board in Lund (LU-818-01) and conforms to the principles outlined in the Declaration of Helsinki.

\section{Consent for publication}

Not applicable.

\section{Competing interests}

The authors declare no potential conflicts of interest with respect to the research, authorship, and/or publication of this article.

\section{Author details \\ 'Department of Clinical Experimental Research, Glostrup Research Institute, Rigshospitalet, Glostrup, Denmark. ${ }^{2}$ Division of Experimental Vascular Research, Department of Clinical Sciences, Lund University Hospital, Lund, Sweden. ${ }^{3}$ Department of Pharmacology, School of Medicine, University of California at Irvine, Irvine, CA, USA. ${ }^{4}$ Department of Drug Design and Pharmacology, Faculty of Health and Medical Sciences, University of Copenhagen, Copenhagen, Denmark. ${ }^{5}$ Department of Internal Medicine, Lund University Hospital, S-22185 Lund, Sweden.}

Received: 18 August 2020 Accepted: 29 October 2020 Published online: 10 November 2020

\section{References}

1. Katsarava Z, Mania M, Lampl C, Herberhold J, Steiner TJ (2018) Poor medical care for people with migraine in Europe - evidence from the Eurolight study. J Headache Pain 19(1):10

2. Buse DC, Loder EW, Gorman JA, Stewart WF, Reed ML, Fanning KM, Serrano D, Lipton RB (2013) Sex differences in the prevalence, symptoms, and associated features of migraine, probable migraine and other severe headache: results of the American Migraine Prevalence and Prevention (AMPP) study. Headache 53(8):1278-1299

3. MacGregor EA, Frith A, Ellis J, Aspinall L, Hackshaw A (2006) Incidence of migraine relative to menstrual cycle phases of rising and falling estrogen. Neurology 67(12):2154-2158

4. Brann DW, Dhandapani K, Wakade C, Mahesh VB, Khan MM (2007) Neurotrophic and neuroprotective actions of estrogen: basic mechanisms and clinical implications. Steroids 72(5):381-405

5. Carswell HV, Macrae IM, Farr TD (2009) Complexities of oestrogen in stroke. Clin Sci (Lond) 118(6):375-389

6. Milner TA, Ayoola K, Drake CT, Herrick SP, Tabori NE, McEwen BS, Warrier S, Alves SE (2005) Ultrastructural localization of estrogen receptor beta immunoreactivity in the rat hippocampal formation. J Comp Neurol 491(2): 81-95

7. Milner TA, McEwen BS, Hayashi S, Li CJ, Reagan LP, Alves SE (2001) Ultrastructural evidence that hippocampal alpha estrogen receptors are located at extranuclear sites. J Comp Neurol 429(3):355-371

8. Hammes SR, Levin ER (2007) Extranuclear steroid receptors: nature and actions. Endocr Rev 28(7):726-741

9. Revankar CM, Cimino DF, Sklar LA, Arterburn JB, Prossnitz ER (2005) A transmembrane intracellular estrogen receptor mediates rapid cell signaling. Science 307(5715):1625-1630

10. Zhang YY, Liu MY, Liu Z, Zhao JK, Zhao YG, He L, Li W, Zhang JQ (2019) GPR30-mediated estrogenic regulation of actin polymerization and spatial memory involves SRC-1 and PI3K-mTORC2 in the hippocampus of female mice. CNS Neurosci Ther 25(6):714-733

11. Hart D, Nilges M, Pollard K, Lynn T, Patsos O, Shiel C, Clark SM, Vasudevan N (2014) Activation of the G-protein coupled receptor 30 (GPR30) has different effects on anxiety in male and female mice. Steroids 81:49-56

12. Edvinsson L, Haanes KA, Warfvinge K, Krause DN (2018) CGRP as the target of new migraine therapies - successful translation from bench to clinic. Nat Rev Neurol 14(6):338-350

13. Edvinsson JCA, Vigano A, Alekseeva A, Alieva E, Arruda R, De Luca C D'Ettore N, Frattale I, Kurnukhina M, Macerola N et al (2020) The fifth cranial nerve in headaches. J Headache Pain 21(1):65

14. Charles A, Pozo-Rosich P (2019) Targeting calcitonin gene-related peptide: a new era in migraine therapy. Lancet 394(10210):1765-1774

15. Haanes KA, Edvinsson L (2019) Pathophysiological mechanisms in migraine and the identification of new therapeutic targets. CNS Drugs

16. Kitazawa T, Hamada E, Kitazawa K, Gaznabi AK (1997) Non-genomic mechanism of 17 beta-oestradiol-induced inhibition of contraction in mammalian vascular smooth muscle. J Physiol 499(Pt 2):497-511

17. Chrissobolis S, Budzyn K, Marley PD, Sobey CG (2004) Evidence that estrogen suppresses rho-kinase function in the cerebral circulation in vivo. Stroke 35(9):2200-2205

18. McNeill AM, Zhang C, Stanczyk FZ, Duckles SP, Krause DN (2002) Estrogen increases endothelial nitric oxide synthase via estrogen receptors in rat cerebral blood vessels: effect preserved after concurrent treatment with medroxyprogesterone acetate or progesterone. Stroke 33(6):1685-1691

19. Pavlovic JM, Allshouse AA, Santoro NF, Crawford SL, Thurston RC, Neal-Perry GS, Lipton RB, Derby CA (2016) Sex hormones in women with and without migraine: evidence of migraine-specific hormone profiles. Neurology 87(1): 49-56

20. Somerville BW (1972) The role of estradiol withdrawal in the etiology of menstrual migraine. Neurology 22(4):355-365

21. Gupta S, McCarson KE, Welch KM, Berman NE (2011) Mechanisms of pain modulation by sex hormones in migraine. Headache 51(6):905-922

22. Warfvinge K, Krause DN, Maddahi A, Grell AS, Edvinsson JC, Haanes KA, Edvinsson $L$ (2020) Oxytocin as a regulatory neuropeptide in the trigeminovascular system: localization, expression and function of oxytocin and oxytocin receptors. Cephalalgia 333102420929027

23. Paxinos G Watson C (2007) The rat brain in stereotaxic coordinates, 6th edn. Academic Press, London

24. Warfvinge K, Edvinsson L (2019) Distribution of CGRP and CGRP receptor components in the rat brain. Cephalalgia 39(3):342-353

25. Forbes DJ, Welt C (1981) Neurogenesis in the trigeminal ganglion of the albino rat: a quantitative autoradiographic study. J Comp Neurol 199(1):133-147

26. Edvinsson JCA, Grell AS, Warfvinge K, Sheykhzade M, Edvinsson L, Haanes KA (2020) Differences in pituitary adenylate cyclase-activating peptide and calcitonin gene-related peptide release in the trigeminovascular system. Cephalalgia 333102420929026

27. Haanes KA, Labastida-Ramirez A, Blixt FW, Rubio-Beltran E, Dirven CM, Danser AH, Edvinsson L, MaassenVanDenBrink A (2019) Exploration of purinergic receptors as potential anti-migraine targets using established pre-clinical migraine models. Cephalalgia 39(11):1421-1434

28. Bryan RM Jr. Eichler MY, Swafford MW, Johnson TD, Suresh MS, Childres WF (1996) Stimulation of alpha 2 adrenoceptors dilates the rat middle cerebral artery. Anesthesiology 85(1):82-90

29. Grande G, Nilsson E, Edvinsson L (2013) Comparison of responses to vasoactive drugs in human and rat cerebral arteries using myography and pressurized cerebral artery method. Cephalalgia 33(3):152-159 
30. Mulvany MJ, Halpern W (1977) Contractile properties of small arterial resistance vessels in spontaneously hypertensive and normotensive rats. Circ Res 41(1):19-26

31. Grande G, Labruijere S, Haanes KA, MaassenVanDenBrink A, Edvinsson L (2014) Comparison of the vasodilator responses of isolated human and rat middle meningeal arteries to migraine related compounds. J Headache Pain 15:22

32. Ohlsson L, Haanes KA, Kronvall E, Xu C, Snellman J, Edvinsson L (2019) Erenumab (AMG 334), a monoclonal antagonist antibody against the canonical CGRP receptor, does not impair vasodilatory or contractile responses to other vasoactive agents in human isolated cranial arteries. Cephalalgia 39(14):1745-1752

33. Edvinsson JCA, Warfvinge K, Krause DN, Blixt FW, Sheykhzade M, Edvinsson L, Haanes KA (2019) C-fibers may modulate adjacent Adelta-fibers through axon-axon CGRP signaling at nodes of Ranvier in the trigeminal system. J Headache Pain 20(1):105

34. Petersen KA, Nilsson E, Olesen J, Edvinsson L (2005) Presence and function of the calcitonin gene-related peptide receptor on rat pial arteries investigated in vitro and in vivo. Cephalalgia 25(6):424-432

35. Patkar S, Farr TD, Cooper E, Dowell FJ, Carswell HV (2011) Differential vasoactive effects of oestrogen, oestrogen receptor agonists and selective oestrogen receptor modulators in rat middle cerebral artery. Neurosci Res 71(1):78-84

36. Malmsjo M, Edvinsson L, Erlinge D (1998) P2U-receptor mediated endothelium-dependent but nitric oxide-independent vascular relaxation. $\mathrm{Br}$ J Pharmacol 123(4):719-729

37. Wihlborg AK, Malmsjo M, Eyjolfsson A, Gustafsson R, Jacobson K, Erlinge D (2003) Extracellular nucleotides induce vasodilatation in human arteries via prostaglandins, nitric oxide and endothelium-derived hyperpolarising factor. Br J Pharmacol 138(8):1451-1458

38. Saito K, Cui H (2018) Emerging Roles of Estrogen-Related Receptors in the Brain: Potential Interactions with Estrogen Signaling. Int J Mol Sci:19(4)

39. Rossetti MF, Cambiasso MJ, Holschbach MA, Cabrera R (2016) Oestrogens and Progestagens: Synthesis and Action in the Brain. J Neuroendocrinol: 28(7)

40. Martin VT, Behbehani M (2006) Ovarian hormones and migraine headache: understanding mechanisms and pathogenesis--part 2. Headache 46(3):365386

41. Couturier EG, Bomhof MA, Neven AK, van Duijn NP (2003) Menstrual migraine in a representative Dutch population sample: prevalence, disability and treatment. Cephalalgia 23(4):302-308

42. MacGregor EA (1996) "menstrual" migraine: towards a definition Cephalalgia 16(1):11-21

43. Gupta S, Mehrotra S, Villalon CM, Perusquia M, Saxena PR, MaassenVanDenBrink A (2007) Potential role of female sex hormones in the pathophysiology of migraine. Pharmacol Ther 113(2):321-340

44. MacGregor EA, Chia H, Vohrah RC, Wilkinson M (1990) Migraine and menstruation: a pilot study. Cephalalgia 10(6):305-310

45. Maasumi K, Tepper SJ, Kriegler JS (2017) Menstrual migraine and treatment options: review. Headache 57(2):194-208

46. Wang D, Zhao J, Wang J, Li J, Yu S, Guo X (2014) Deficiency of female sex hormones augments PGE2 and CGRP levels within midbrain periaqueductal gray. J Neurol Sci 346(1-2):107-111

47. Cetinkaya A, Kilinc E, Camsari C, Ogun MN (2020) Effects of estrogen and progesterone on the neurogenic inflammatory neuropeptides: implications for gender differences in migraine. Exp Brain Res 238(11):2625-2639

48. Aloisi AM (2003) Gonadal hormones and sex differences in pain reactivity. Clin J Pain 19(3):168-174

49. May A (2017) Understanding migraine as a cycling brain syndrome: reviewing the evidence from functional imaging. Neurol Sci 38(Suppl 1): $125-130$

50. Craft RM (2007) Modulation of pain by estrogens. Pain 132(Suppl 1):S3-12

51. Fillingim RB, King CD, Ribeiro-Dasilva MC, Rahim-Williams B, Riley JL 3rd (2009) Sex, gender, and pain: a review of recent clinical and experimental findings. J Pain 10(5):447-485

52. McNeill AM, Duckles SP, Krause DN (1996) Relaxant effects of 17 betaestradiol in the rat tail artery are greater in females than males. Eur J Pharmacol 308(3):305-309

\section{Publisher's Note}

Springer Nature remains neutral with regard to jurisdictional claims in published maps and institutional affiliations.

Ready to submit your research? Choose BMC and benefit from:

- fast, convenient online submission

- thorough peer review by experienced researchers in your field

- rapid publication on acceptance

- support for research data, including large and complex data types

- gold Open Access which fosters wider collaboration and increased citations

- maximum visibility for your research: over $100 \mathrm{M}$ website views per year

At BMC, research is always in progress.

Learn more biomedcentral.com/submissions 